\title{
Simplified flux prediction in direct-contact membrane distillation using a membrane structural parameter
}

Guiying Rao ${ }^{\text {a }}$, Sage R. Hiibel ${ }^{\mathrm{a}}$, and Amy E. Childress ${ }^{\mathrm{b}, *}$

${ }^{a}$ Department of Civil and Environmental Engineering, University of Nevada Reno, Reno, NV 89557, USA

${ }^{\mathrm{b}}$ Astani Department of Civil and Environmental Engineering, University of Southern California, Los Angeles, CA 90089-2531, USA

* Corresponding author. Tel.: +1 213740 6304, fax: +1 213744 1426, e-mail address: amyec@usc.edu

(C) 2014. This manuscript version is made available under the Elsevier user license http://www.elsevier.com/open-access/userlicense/1.0/ 


\begin{abstract}
A priori water flux prediction is desirable when conducting membrane distillation (MD) studies, however existing models are complicated with inconsistent mass transfer mechanism assumptions. To develop a simplified model that can be used to predict the relative magnitudes of water fluxes for a group of MD membranes, correlation analyses were performed between water flux and 28 structural parameters. Four parameters were found to be highly correlated with water flux: $\varepsilon / \delta, \varepsilon / \tau \delta, 1 / \tau \delta$, and $C_{m}$. $C_{m}$ is a newly introduced structural parameter that contains noncoupled membrane properties but still carries the physical meaning of a relationship between $\delta$ and $\varepsilon$, and is determined by simple and reliable measurements using inexpensive analytical equipment. The correlation result between water flux and $C_{m}$ suggests $C_{m}$ is a good structural parameter for MD flux prediction. The flux prediction errors for membranes with pore sizes from 0.1 to $0.9 \mu \mathrm{m}$ were generally smaller for the model developed with $C_{m}$ than for the dusty gas model. In addition to the new structural parameter and model, this study also makes available to the literature a detailed collection of MD membrane properties and their water flux values that will assist others in membrane selection, development, and application.
\end{abstract}




\section{Keywords}

Membrane distillation; Membrane structural parameter; Flux prediction model; Membrane characterization 


\section{Introduction}

\subsection{Membrane distillation}

Membrane distillation (MD) is a thermally-driven process in which separation occurs through a phase change to produce clean water. The driving force in MD is the vapor pressure gradient, resulting from the temperature difference across the membrane. Among all types of MD, direct-contact MD (DCMD) is the most commonly used configuration in lab-scale research [1]. In DCMD, two solutions at different bulk temperatures are circulated on either side of a hydrophobic microporous membrane. Temperatures of the feed solution can range from $30-90{ }^{\circ} \mathrm{C}[2$, 3 ], which makes it feasible to be combined with low-grade heat sources. DCMD has been used to treat feed waters with high fouling and scaling potentials, such as industrial wastewater [4, 5], water from salt lakes [6], RO brines [7, 8], and produced water from the oil and gas industry [9-11], because the driving force of DCMD does not decrease significantly with increasing water salinity. DCMD is also well suited to treat feed waters with low fouling and scaling potentials where targeted removal or polishing is desired because DCMD achieves near 100\% salt and organic rejection [12,13]. Examples include impaired water containing endocrine disrupting compounds [14]; brackish water contaminated with fluoride [15]; groundwater with heavy metals [16]; and feed waters with urine and hygiene wastewater [17]. In some DCMD applications (particularly with low fouling and scaling feedwaters) obtaining high water flux is desirable while in other applications (with high fouling and scaling feedwaters) it is not, thus a priori water flux prediction is desirable for membrane selection. Because MD water flux is affected by membrane properties, feed water properties, and operating conditions [18], if a group of MD membranes is operated on the same feedwater at specific operating conditions, only the membrane properties will affect the relative magnitude of water flux.

\subsection{Existing mass transfer models for flux prediction in MD}

Water flux $\left(N_{i}\right)$ through an MD membrane is given as:

$$
N_{i}=B \Delta P_{i}
$$

where $B$ is the membrane mass transfer coefficient and $\Delta P_{i}$ is the water vapor pressure gradient across the membrane. Here, subscript $i$ is used to represent water vapor and subscript $j$ is used to represent air. Water vapor pressure $\left(P_{i}\right)$ for both the feed stream and the distillate stream is expressed using the Antoine equation [19, 20]:

$$
P_{i}=\exp \left(23.328-\frac{3841}{T-45}\right)
$$

where $T$ is the temperature of the respective stream. The dusty gas model is often used to estimate water flux in MD, where four mass transfer mechanisms (surface diffusion, Knudsen diffusion, molecular diffusion, and viscous flow) may occur; the thermal circuit representation is given in Fig. 1. The complete expression of the dusty gas model is complex, thus surface diffusion, which only occurs when membrane pore sizes are smaller than $0.02 \mu \mathrm{m}$ [21], is typically not included so as to simplify MD flux prediction [2,22]. MD water flux without consideration of surface diffusion is given as:

$$
N_{i}=N_{i}^{D}+N_{i}^{V}
$$

where $N_{i}^{D}$ and $N_{i}^{V}$ are the diffusive (combined Knudsen and molecular) flux and viscous flux of water vapor, respectively. In its most general form, the dusty gas model applicable to MD is given by two equations [2]:

$$
\begin{aligned}
& \frac{N_{i}^{D}}{\frac{2 r \varepsilon}{3 \tau \delta}\left(\frac{8 R T_{m}}{\pi M_{i}}\right)^{0.5}}+\sum_{j=1 \neq i}^{n} \frac{P_{j} N_{i}^{D}-P_{i} N_{j}^{D}}{\frac{\varepsilon}{\tau \delta} P D_{i j}}=\frac{1}{R T} \Delta P_{i} \\
& N_{i}^{V}=\frac{P_{i}}{8 R T_{m} \mu} \frac{r^{2} \varepsilon}{\tau \delta} \Delta P
\end{aligned}
$$

where $r, \varepsilon, \tau$, and $\delta$ are the membrane pore radius, porosity, tortuosity, and thickness, respectively; $R$ is the universal gas constant; $T_{m}$ is the average temperature of the membrane; $M_{i}$ is the molecular weight of water vapor; $P_{j}$ is the air pressure inside the membrane pores; $N_{j}^{D}$ is the diffusive flux of air; $P$ is the total pressure; $D_{i j}$ is the ordinary diffusion coefficient; $\mu$ is the fluid viscosity; and $\Delta P$ is the transmembrane pressure. Two equations for $P D_{i j}$ are given in the literature $[2,12,23]$ :

$$
P D_{i j}\left(\mathrm{kPa} \mathrm{m}^{2} / \mathrm{s}\right)=4.46 \times 10^{-9} \times T_{m}^{2.334}
$$

and [22, 24]: 


$$
P D_{i j}\left(\mathrm{kPa} \mathrm{m}^{2} / \mathrm{s}\right)=1.895 \times 10^{-8} \times T_{m}^{2.072}
$$

Because of temperature polarization, the temperatures at the membrane surfaces (feed and distillate sides) are different from the bulk temperatures, thus the dynamic conditions inside the membrane module have to be considered (with hydraulic pressures, salinities, heat capacities, viscosities, and flow rates on both the feed and distillate sides, spacer properties if spacers are used, and membrane module dimensions) when determining the average membrane temperature $\left(T_{m}\right)$ [19, 25-27]. Also, because hydraulic pressures always exist in flowing streams, membrane compaction may occur during MD testing, resulting in modified membrane properties $(r, \varepsilon, \tau$, and $\delta)[28$, 29]. Both temperature polarization and membrane compaction complicate the mass transfer equations. In seeking simplification of flux prediction, some investigations have assumed that viscous flow is negligible in DCMD due to the lack of a hydraulic pressure gradient [12,22]; in these cases, only Eq. 4 is used to predict water flux. Other investigations assert that viscous flow cannot be neglected, especially for membranes with large (e.g., $>0.3 \mu \mathrm{m})$ pore sizes where the mean free path of water vapor in air is much greater than the membrane pore size [19, 30]. In these cases, a membrane pore size distribution instead of the average pore size has been used for mass transfer modeling $[22,31,32]$. The complicated model expressions and contradictory assumptions from the literature for the mass transfer mechanisms make prediction of water flux using the simplified dusty gas model cumbersome and ambiguous.

\subsection{Existing membrane property parameters}

If experimental operating conditions and solution chemistries are kept constant, then only the membrane properties will affect water flux. Considering this, further simplifications of the dusty gas model in the literature have used membrane property parameters (also referred to as membrane morphology parameters) to qualitatively analyze water flux. From Eqs. 4 and 5, membrane property parameters affecting water flux are $\varepsilon / \tau \delta$, $r \varepsilon / \tau \delta$, or $r^{2} \varepsilon / \tau \delta$ for molecular diffusion, Knudsen diffusion, and viscous flow, respectively. It is expected that membranes with greater $\varepsilon / \tau \delta, r \varepsilon / \tau \delta$, or $r^{2} \varepsilon / \tau \delta$ will have higher water fluxes [2, 24, 33-36]. It is also generally agreed that higher water fluxes occur for MD membranes with higher porosity [33, 37, 38] or lower tortuosity [23, 39].

It is unclear to what extent membrane pore size affects water flux since the role of membrane pore size is not the same in $\varepsilon / \tau \delta, r \varepsilon / \tau \delta$, and $r^{2} \varepsilon / \tau \delta$. Lawson et al. [37] found that water flux increased with increasing pore size. Mericq et al. [40] found that the Knudsen permeability ( $B \propto r \varepsilon / \tau \delta$; $r$ included) of the membrane strongly affected water flux. However, in a couple of observations, water flux was found to be highly sensitive to the characteristic parameter $\varepsilon / \tau \delta[27,34]$ and only slightly sensitive to pore size [27]. Ali et al. [36] also observed no dramatic increase of the water flux with increasing pore size, especially when the pore size was smaller than $0.3 \mu \mathrm{m}$.

Although thickness is generally included in the membrane property parameters, some studies discounted its role and utilized $\varepsilon / \tau, r \varepsilon / \tau$, and $r^{2} \varepsilon / \tau$. Lawson et al. [37] found that flux increased as the membrane parameter

$\tau \delta$ increased. Bonyadi et al. [33] and El-Bourawi et al. [38] found that thickness was important because thinner membranes have reduced mass transfer resistance but they also found that flux did not monotonically increase with thickness reduction because of increased conductive heat loss through the membrane.

Although several membrane property parameters have been analyzed in the literature, there are contradictory observations about their effects on water flux (with the exception of porosity and tortuosity). Furthermore, only qualitative analyses between water flux and membrane property parameters were given; these enable the evaluation of trends but not the prediction of specific values of flux. Uniform terminology for the combinations of membrane property parameters also does not exist: membrane constant, membrane parameter, model parameter, structural parameter, morphology parameter, membrane factor, and characteristic parameter have all been used in the literature. The term membrane structural parameter will be used in this work and will refer to a single membrane-specific property or combination of properties.

\subsection{Concern of coupled membrane properties in structural parameters}

Often, membrane structural parameters given in the literature $\left(\varepsilon / \tau \delta, r \varepsilon / \tau \delta, r^{2} \varepsilon / \tau \delta, r \varepsilon / \tau, r^{2} \varepsilon / \tau, \varepsilon / \tau\right.$, and $\tau \delta$ ) may have coupled membrane properties. For example, porosity may be calculated as a function of thickness [35, 37, 41, 42] and tortuosity is frequently calculated as a function of porosity [34, 35, 39, 43]. Thus, errors in the thickness measurement will be propagated into the porosity determination and then into the tortuosity determination. The presence of errors in measurements as straightforward as thickness measurements can be seen by comparing membrane thickness values for the same membrane from different sources (e.g., from [44-47] for the GVHP and HVHP membranes). Although membrane structural parameters may be decoupled by evaluating more of the membrane properties experimentally, as has been done in some investigations (e.g., [33, 48, 49]), this comes with additional cost of time, effort, and equipment. Therefore, a membrane structural parameter that requires few 
laboratory measurements and does not include coupled membrane properties would be very useful to make a priori flux predictions.

\subsection{Objective}

Because low water flux is preferred when treating feedwaters with high fouling and scaling potentials and high water flux is preferred when treating less challenging feedwaters (Section 1.1), a simplified model that can predict the relative magnitudes of water fluxes for a group of MD membranes would be useful. Membrane structural parameters have been used to simplify mass transfer modeling in MD, however, no flux predictions with either absolute or relative magnitudes have been made using these parameters, and also, these parameters may contain coupled properties. In this work, a new membrane structural parameter is introduced to provide a priori assessment of the relative magnitude of water flux. First, a membrane structural parameter with no coupled parameters and requiring simple and reliable laboratory measurements was identified. Second, an empirical model based on the new structural parameter was developed to predict water flux for single-layer membranes and composite membranes. Predictions from this model were compared with flux predictions of existing mass transfer models. Third, flux predictions from this model were correlated with water fluxes for membranes with a range of pore sizes. This study also makes available to the literature a detailed collection of MD membrane properties and their water flux values that will assist others in membrane selection, development, and application.

\section{Materials and methods}

\subsection{MD membrane water flux test}

Membrane water flux was evaluated using a bench-scale DCMD configuration (Fig. 2). Four liters of doubledistilled water were added to both the feed and distillate reservoirs. The feed stream was maintained at $60^{\circ} \mathrm{C}$ using a flow-through heater (STFT-1500-120, TruHeat, Allegan, MI). The distillate stream was held at $20^{\circ} \mathrm{C}$ using a recirculating chiller (NESLAB ThermoFlex 1400, Thermo Fisher Scientific, Newington, NH). Temperatures were monitored using four resistance temperature detectors (PRTF-10, Omega, Stamford, CT) coupled to a 4-channel analog input module (NI 9217, National Instruments, Austin, TX) at the inlet and outlet of the feed and distillate loops of the membrane module. The membrane module utilized a flat-sheet membrane with $118 \mathrm{~cm}^{2}$ of effective membrane surface area. Two spacers were used, one on the feed side and one on the distillate side of the membrane, to generate turbulence and reduce polarization effects. The feed and distillate streams were circulated countercurrently on their respective sides of the membrane at $1.5 \mathrm{~L} / \mathrm{min}$. As water evaporated through the membrane, the excess water from the distillate reservoir overflowed into a beaker on an analytical balance and the overflow rate was used to calculate water flux. For each membrane, water fluxes of three membrane samples were measured and the average water flux was calculated.

\subsection{Membrane characterization}

A total of 19 flat-sheet membranes (10 single-layer, 9 composite) were tested. The membrane properties provided by the manufacturers are listed in Table 1 and the additional measurements performed to provide further membrane characterization are described below. The single-layer membranes were used directly for all characterization measurements. The composite membranes were used intact for all measurements except porosity, which required peeling of the active layer off the support layer. Care was taken to ensure as minimal disruption as possible to the peeled active and support layers.

\subsubsection{Average pore size measurement}

Intact membranes were used to determine the average pore size of the single-layer membranes and the active layers of the composite membranes using the gas permeation test with compressed air [50,51]. The permeation flux of air through the dried membrane was measured at room temperature using transmembrane pressures from 10 to $100 \mathrm{kPa}$. Pore diameter $(d)$ was then calculated as:

$$
d=\frac{16}{3}\left(\frac{B_{o}}{K}\right)\left(\frac{2 R T}{\pi M_{j}}\right)^{0.5}
$$

where $B_{o}$ is the geometric factor of a membrane; $K$ is the permeability coefficient; and $M_{j}$ is the molecular weight of air [52].

\subsubsection{Porosity and tortuosity measurements}

The porosity $(\varepsilon)$ of the single-layer membranes and peeled active and support layers of the composite membranes was determined by: 


$$
\varepsilon=1-\frac{\rho_{m}}{\rho_{p}}
$$

where $\rho_{m}$ is the density of the membrane sample and $\rho_{p}$ is the reported density of the polymer material [35]. The membrane sample density, $\rho_{m}$, for the single-layer membrane was calculated directly from the mass and dimensions of a membrane sample, excluding the pore space in the material. Values of $\rho_{p}$ used were $2200 \mathrm{~kg} / \mathrm{m}^{3}$ for polytetrafluoroethylene (PTFE) [49,53], $900 \mathrm{~kg} / \mathrm{m}^{3}$ for polypropylene (PP) [53], and $1780 \mathrm{~kg} / \mathrm{m}^{3}$ for polyvinylidene fluoride (PVDF) [54]. Although additives may be included during the membrane manufacturing process [55], and could cause the actual density of the membrane material to be different from the reported polymer density, the difference is assumed negligible due to the very small additive amounts. Zhang et al. [35] used the reported polymer density in their porosity calculation and claimed a density error of less than 3\%. Ruskowitz et al. [56] used energy dispersive spectrometry (EDS) surface analysis (0.3-0.5 wt\% detection limit) on a virgin PTFE sample (Membrane $\mathrm{D}$, Table 1), and detected only carbon and fluorine on the membrane sample.

The tortuosity $(\tau)$ of each single-layer membrane was calculated by [23, 57]:

$$
\tau=\frac{(2-\varepsilon)^{2}}{\varepsilon}
$$

and the tortuosity of the active layer $\left(\tau_{a}\right)$ of the composite membrane was calculated by:

$$
\tau_{a}=\frac{\left(2-\varepsilon_{a}\right)^{2}}{\varepsilon_{a}}
$$

where $\varepsilon_{a}$ is the porosity of the active layer. Tortuosity of the non-woven support layer $\left(\tau_{s}\right)$ of the composite membrane was calculated by $[43,58]$ :

$$
\tau_{s}=\frac{1}{\varepsilon_{s}}
$$

where $\varepsilon_{s}$ is the porosity of the composite membrane support layer. The porosity-tortuosity relationship in Eq. 12 is different from Eqs. 10 and 11 because non-woven support layers are loosely packed, with structures similar to random spheres or clusters; while single-layer membranes and active layers of composite membranes are spongy, with structures similar to the interstices between closely packed spheres $[43,58]$. Tortuosity of the scrim support layer of the composite membrane was assumed to be 1 [59].

\subsubsection{Membrane thickness measurement}

The thickness $(\delta)$ of the single-layer membranes and the active layer and support layer of the composite membranes were measured from scanning electron micrographs of membrane cross-sections. Prior to measurement, the intact membranes were immersed in liquid nitrogen and cut with a razor blade. The thicknesses of the active layer and the support layer of the composite membranes were measured separately on the same scanning electron micrograph (no peeling was necessary). Each thickness was measured on three different sections of the membrane and the average thickness was calculated.

\subsubsection{Contact angle measurement}

Contact angle $(\theta)$ was measured as an indication of membrane hydrophobicity. A commercial goniometer (RaméHart, Mountain Lakes, NJ) was used to perform captive-bubble measurements on intact membranes to determine the contact angle of the single-layer membranes and composite membrane active layers. By immersing the membrane sample into a water solution and completely hydrating it, the contact angle measurement is less influenced by pores and swelling [60]. For each membrane, triplicate contact angles were measured on three samples, resulting in nine contact angles measured per membrane, and the average contact angle was calculated.

\subsubsection{Liquid-entry pressure measurement}

Liquid-entry pressure (LEP) is the pressure that must be applied to a water solution to penetrate into dry membrane pores. It is a function of the membrane properties and the liquid properties. The expression for LEP is:

$$
P_{l}-P_{j}=\frac{2 B_{o} \gamma_{l} \cos \theta}{r_{\max }}<L E P
$$

where $P_{l}$ is the pressure of the liquid on the membrane surface; $\gamma_{l}$ is the liquid surface tension; and $r_{\max }$ is the largest membrane pore radius [61]. The experimental apparatus reported by Smolders et al. [48] was used to perform LEP 
measurements on intact membranes to determine the LEP of single-layer membranes and composite membrane active layers. Each membrane was placed in a static stainless-steel cell filled with double-distilled water. The water pressure was increased in increments of $5 \mathrm{kPa}$ and maintained for one minute at each pressure; the pressure at which continuous flow was observed on the distillate side was considered to be the membrane LEP.

\subsubsection{Percent of open surface area of the support layer measurement}

Scanning electron micrographs with 35x magnification were used to determine the percent of open surface area (POSA) of the support layers. The scrim support layer had a uniform pore structure (Fig. 3a), thus the POSA was calculated by dividing the total pore area (function of pore area and pore number) by the whole membrane sample area [34]. Because of the non-uniform pore structure of the non-woven support layer (Fig. 3b), the POSA was determined using the grid method with the scanning electron micrographs.

\subsection{Model development and validation for water flux prediction}

Scatterplots and correlation matrices between water flux and the membrane structural parameters were developed and analyzed using Minitab® 15.1.0.0 with the goal of identifying the structural parameters with the strongest correlation with water flux. For selected structural parameters, a linear regression analysis was performed between water flux and the structural parameter to develop a water flux prediction model. To ensure the robustness of the model, the process was performed three times in total with membranes from Table 1 randomly selected each time for the linear regression. The single-layer membranes and the composite membranes were tested separately from each other.

The models developed above were validated both internally and externally. For internal validation, the sum of the estimated standard deviations of the regression coefficients ( $s\left\{b_{0}\right\}$ and $s\left\{b_{1}\right\}$ ), squared errors (SSE), mean squared error (MSE), adjusted $R^{2}$, and predicted residual sums of squares (PRESS) criteria were used [62]. All criteria were obtained from the Minitab® regression output. Typically, a model with small s $\left\{b_{0}\right\}, \mathrm{s}\left\{b_{1}\right\}$, SSE, MSE, PRESS, and high adjusted $R^{2}$ will fit well and result in small errors between the predicted water flux and the measured water flux for the membranes used to develop the model. For external validation, the mean squared prediction error (MSPR) was used. If the MSPR to MSE ratio of a model is smaller than the critical F-test value $(p<0.05)$, the model is valid, and vice versa [63]. For a valid model, if the MSPR is much smaller than or fairly close to the MSE, the MSE will give an appropriate measure of the predictive capability of the model. If the MSPR is much greater than the MSE, then the MSPR should be used as an indicator of the predictive capability of the model [64]. A model with a smaller MSPR or MSE (depending on which one is used) is expected to have a better predictive capability [64].

\section{Results and discussions}

3.1. Membrane property characterization and flux test results

The properties of the single-layer membranes and the active layers of the composite membranes, along with the intact membrane water fluxes are given in Table 2 . The average pore sizes of the single-layer membranes $(0.1-0.5$ $\mu \mathrm{m}$ excluding membrane $\mathrm{D})$ and the composite membrane active layers $(0.2-0.6 \mu \mathrm{m})$ are comparable and generally within the range reported in the literature $(0.2-1 \mu \mathrm{m})[1,35,65]$. Membrane porosities for the single-layer membranes (37-85\%) and the composite membrane active layers (47-90\%) are also comparable and generally within the range reported in the literature $(30-85 \%)$ [38, 39]. It follows from Eq. 10 that the tortuosities are also comparable (1.58-4.02 for the single-layer membranes except Membrane I and 1.59-5.05 for the active layers of the composite membranes) and consistent with the literature (1.21-6.84) [43]. The thicknesses of the single-layer membranes (39 to $205 \mu \mathrm{m}$ ) are similar to those reported in the literature (40 to $250 \mu \mathrm{m}$ ) [1]; they span a broader range than the thicknesses of the composite membrane active layers $(27-59 \mu \mathrm{m})$. This is because single-layer membranes must be thick enough to be mechanically strong and to minimize conductive heat loss but thin enough to minimize the mass transfer resistance, while composite membranes must have thin active layers to reduce the mass transfer resistance and the support layers will provide mechanical strength and reduce conductive heat loss. The contact angles of the single-layer membranes $\left(109-131^{\circ}\right)$ and the composite membrane active layers $\left(106-128^{\circ}\right)$ are similar and are comparable with what has been reported in the literature $\left(110-165^{\circ}[58,66]\right)$. The LEP values of the single-layer membranes (141-430 kPa) and the composite membrane active layers (95-438 kPa) are comparable and generally within the reported range $(48-463 \mathrm{kPa})[39]$.

The single-layer membrane water fluxes $\left(11-35 \mathrm{~L} / \mathrm{m}^{2} \mathrm{~h}\right)$ are within the reported flux range $\left(4-42 \mathrm{~L} / \mathrm{m}^{2} \mathrm{~h}\right.$ at feed-side temperatures near $40{ }^{\circ} \mathrm{C}$ and flow rates from 0.02 to $0.23 \mathrm{~m} / \mathrm{s}$ for DCMD [39]); it should be noted that other experimental conditions including the distillate-side temperature and type of membrane spacers will also affect 
water flux. The lowest water flux occurs for Membrane I, which has the lowest porosity (37\%) (hence, highest tortuosity $(7.07))$ and the smallest average pore size $(0.1 \mu \mathrm{m})$. Membrane $\mathrm{G}$ has similar pore size $(0.11 \mu \mathrm{m})$ as Membrane I, but the water flux is $54 \%$ higher than that of Membrane I, which is likely due to the much greater porosity $(84 \%$; hence, much lower tortuosity $(1.60))$. The composite membrane water fluxes fall within a more narrow range $\left(22-28 \mathrm{~L} / \mathrm{m}^{2} \mathrm{~h}\right)$ with all but two membranes having a water flux above $25 \mathrm{~L} / \mathrm{m}^{2} \mathrm{~h}$. The wide range of membrane properties and experimental water fluxes of the single-layer membranes is beneficial in developing the model to predict water fluxes.

Table 3 provides the characterization results of the composite membrane support layers. The thicknesses of the nonwoven structural support layers $(133-283 \mu \mathrm{m})$ are greater than the thicknesses of the scrim structural support layers (50-77 $\mu \mathrm{m}$ except Membrane $\mathrm{O}$ with a thickness of $255 \mu \mathrm{m}$ ). The porosities of the non-woven structural support layers (66-81\%) are higher than the porosities of the scrim structural support layers (31-59\%), while the POSA are generally an order of magnitude lower for the non-woven structural support layers than the scrim structural support layers. This phenomena has been reported previously [58]. Because the larger POSA of the scrim structure benefits the mass transfer while the lower porosity limits the mass transfer, the effect of these on flux is not obvious.

\subsection{Model development and validation for single-layer membranes}

3.2.1. Identification of structural parameters that have high correlations with water flux As discussed in Section 1.3, pore size, porosity, tortuosity, and thickness may each affect water flux in MD. In this work, four characteristics $(r, \varepsilon, 1 / \tau, 1 / \delta)$ were considered in various combinations $\left(r^{n} \varepsilon / \tau \delta, r^{n} \varepsilon / \delta, r^{n} \varepsilon / \tau\right.$, $r^{n} / \tau \delta, r^{n} \varepsilon, r^{n} / \tau, r^{n} / \delta$, and $r^{n}$ ), where $n$ is 0,1 , or 2 . Additional membrane properties, including $\theta, 1 /$ LEP, $1 /$ thermal conductivity $\left(1 / k_{m}\right)$, and $1 /$ heat transfer coefficient $\left(1 / h_{m}\right)$ were also investigated to ensure a comprehensive analysis of possible structural parameters (28 total parameter combinations were tested). Calculations of $k_{m}$ and $h_{m}$ were performed as reported in the literature [2,12,45]. Overall, the structural parameters were classified into three groups: 1) those already reported in the literature: $\varepsilon / \tau \delta, r \varepsilon / \tau \delta, r^{2} \varepsilon / \tau \delta, \varepsilon / \tau, r \varepsilon / \tau, r^{2} \varepsilon / \tau, 1 / \tau \delta$. $r, \varepsilon$, and $1 / \delta$; 2) basic membrane properties and their reciprocals that were not included in the first group: $1 / \tau$, $1 / \mathrm{LEP}, 1 / k_{m}$, and $1 / h_{m}$; and 3) others: $r \varepsilon / \delta, r^{2} \varepsilon / \delta, \varepsilon / \delta, r^{2} \varepsilon, r \varepsilon, r^{2} / \delta, r / \delta, r / \tau \delta, r^{2} / \tau \delta, r / \tau, r^{2} / \tau$, and $r^{2}$. Membrane contact angle, $\theta$, was eventually removed from consideration as a structural parameter to predict water flux in this investigation because there was little range in the contact angle of the single-layer membranes (Table 2).

To identify the structural parameters that correlate well with water flux, a correlation analysis between water flux and each structural parameter was first performed for the ten single-layer membranes. Although investigations of the effects of membrane pore size, porosity, and inverse thickness on water flux have been discussed in the literature (Section 1.3), the correlation results in Table 4 (correlation coefficient, $\beta$, from 0.243 to 0.428 ) suggest that none of the parameters alone can be used to adequately estimate water flux. The structural parameters $\varepsilon / \delta, \varepsilon / \tau \delta$, and $1 / \tau \delta$ all correlate well with water flux ( $\beta$ from 0.638 to 0.781 ), and those correlation observations are also supported by the scatterplots in Appendix A; thus, these structural parameters may be used to predict water flux. Care should be taken, however, because the three structural parameters include membrane properties that may be coupled, which can lead to error propagation as discussed in Section 1.4.

To avoid the use of coupled membrane properties, a structural parameter that can be measured independently but maintains the physical meaning of those membrane properties that may affect water flux (e.g., thickness and porosity) is preferred. In this regard, membrane porosity (Eq. 9) can be expressed as [35]:

$$
\varepsilon=1-\frac{m}{\rho_{p} \times l \times w \times \delta}
$$

$w$ here $m, l$, and $w$ are the mass, length, and width, respectively, of the membrane sample. Eq. 14 can be used to decouple porosity and thickness by incorporating the constant membrane properties $\left(m, l, w\right.$, and $\left.\rho_{p}\right)$ into a new structural parameter termed the membrane constant $\left(C_{m}\right)$ :

$$
C_{m}=\frac{\rho_{p} \times l \times w}{m}
$$

The physical relationship between the membrane constant, porosity, and thickness can be seen by combining Eqs. 14 and 15:

$$
C_{m}=\frac{1}{\delta(1-\varepsilon)}
$$


The correlation analysis between water flux and $C_{m}$ for the 10 single-layer membranes was performed and a correlation of $\beta=0.714$ was observed (last row of Table 4), suggesting it was a good structural parameter for flux prediction.

Because $C_{m}$ is not based on thickness or porosity measurements (Eq. 15), constant flux will be predicted during membrane compaction periods. To experimentally validate this, four randomly selected membranes were compacted under feed-side pressures up to $100 \mathrm{kPa}$ in DCMD. No flux change was observed for the four membranes; similar phenomena have also been reported by Cath et al. [28]. Although membrane compaction may occur, it may not be significant enough to measurably decrease flux. If the membrane were to be highly compacted, flux decline would likely occur and would not be predicted by $C_{m}$, thus using $C_{m}$ to estimate water flux does have practical limitations. It should also be noted that $C_{m}$ can only be used to estimate the steady-state water flux and not dynamic water flux behavior such as that frequently observed in the initial stages of an MD flux test [67-69].

3.2.2. Model development and validation using the membrane constant

A simple linear regression model based on $C_{m}$ was used to predict water flux under the given experimental conditions. The model was expressed as:

$$
\hat{N}_{i}=b_{0}+b_{1} C_{m}
$$

where $\hat{N}_{i}$ is the predicted water flux and $b_{0}$ and $b_{1}$ are the regression constants. Because the pore sizes of a typical MD membrane range from 0.2 to $1.0 \mu \mathrm{m}[1,35,65]$ and are recommended to be smaller than $0.6 \mu \mathrm{m}$ to prevent wetting [39, 67, 70], only the seven single-layer membranes with pore sizes from 0.18 to $0.51 \mu \mathrm{m}$ were used during model development. Three independent test sets were performed; each test set used five membranes randomly selected for model development and the remaining two for model validation. In Test Set 1, Membranes B and E were used to validate the model; in Test Set 2, Membranes H and J were used; and in Test Set 3, Membranes A and $\mathrm{C}$ were used. The linear regression model was also used to predict water flux based on the other three well correlated structural parameters $\left(\varepsilon / \tau \delta, 1 / \tau \delta\right.$, and $\varepsilon / \delta$ ) simply by replacing $C_{m}$ in Eq. 17 with $\varepsilon / \tau \delta, 1 / \tau \delta$ and $\varepsilon / \delta$, respectively. Results using $\varepsilon / \delta$ revealed a nonlinear relationship with water flux for all three tests ( $p>0.14$; results not shown) and was thus dropped from further model development. The linear regression results for $C_{m}, \varepsilon / \tau \delta$, and $1 / \tau \delta$ are given in Table 5. Linear relationships are observed $(p \leq 0.1)$ for all three. The residual plots (Appendix B) for each structural parameter suggest that it is reasonable to use the linear regression analysis.

In Table 5, the calculated MSPR to MSE ratios are smaller than the critical $\mathrm{F}_{0.05}$ value (5.786) for all tests, thus the developed models are valid to predict water flux for the membranes in the model validation group. In Test Set 1, no single structural parameter is consistently better than the others for the model development considering all model criteria (i.e., none has a consistently lower $\mathrm{s}\left\{\mathrm{b}_{0}\right\}, \mathrm{s}\left\{\mathrm{b}_{1}\right\}$, SSE, PRESS, and MSE and a higher adjusted $\mathrm{R}^{2}$ ); however, the model developed using $C_{m}$ has a better predictive capability due to the smaller MSE. The MSE criterion was used because the MSPR was similar to the MSE for each structural parameter. In Test Set 2, the model developed using $C_{m}$ has lower s $\left\{b_{0}\right\}, \mathrm{s}\left\{b_{1}\right\}$, SSE, PRESS, and MSE and a higher adjusted $R^{2}$ than the models developed using $\varepsilon / \tau \delta$ and $1 / \tau \delta$, indicating that $C_{m}$ is a better structural parameter for the model development. It should be noted however, that the predictive capability of this model (MSPR of 20.71) is not as good as the one developed using $\varepsilon / \tau \delta$ (MSE of 12.58). The MSPR criterion was used for $C_{m}$ because the MSPR was much greater than the MSE; while the MSE criterion was used for $\varepsilon / \tau \delta$ because the MSE was close to the MSPR. In Test Set 3 , the structural parameter $\varepsilon / \tau \delta$ is identified as a better structural parameter for the model development (lower $\left\{\left\{b_{0}\right\}, \mathrm{s}\left\{b_{1}\right\}\right.$, SSE, PRESS, and MSE and a higher adjusted $R^{2}$ ) and the model has a better predictive capability due to the smaller MSE. The MSE criterion was used because the MSE was close to or much larger than the MSPR for each structural parameter. Overall, the models developed using $C_{m}$ and $\varepsilon / \tau \delta$ have better flux prediction performance than the model developed using $1 / \tau \delta$. Because the characterization of the membrane constant requires only basic and independent measurements (mass, length, and width of the membrane sample) that can be obtained with inexpensive analytical equipment (a ruler and a balance), less cost is associated with the measurement as compared to $\varepsilon / \tau \delta$, where the thickness measurement must be determined using scanning electron micrographs. Additionally, the problem of coupled parameters may exist between porosity, tortuosity, and thickness with $d \tau \delta$.

Comparing the results of the three test sets using $C_{m}$, the model developed in Test Set 1 has the smallest MSE or MSPR (depending on which one is used) compared to the models developed in Test Sets 2 and 3. Therefore, this model has the smallest flux prediction errors for the membranes used in the model validation process. The model developed in Test Set 2 has the lowest $s\left\{b_{0}\right\}, s\left\{b_{1}\right\}$, SSE, PRESS, and MSE and the highest adjusted $\mathrm{R}^{2}$ compared to the models developed in Test Sets 1 and 3, thus it has the smallest flux prediction errors for the membranes used in the model development process. Because five out of the seven membranes had better flux predictions using the 
model developed in Test Set 2, this model was taken as the final model for flux prediction under the current experimental conditions. The model is expressed as:

$$
\hat{N}_{i}=10.1+318 \times C_{m}
$$

where the units of $\hat{N}_{i}$ and $C_{m}$ are $\mathrm{L} / \mathrm{m}^{2} \mathrm{~h}$ and $\mu \mathrm{m}^{-1}$, respectively.

\subsubsection{Flux prediction for membranes with pore sizes outside the typical range}

The model (Eq. 18) was also used to predict water flux for membranes with pore sizes outside the range used for the model development $(d<0.18$ or $>0.51 \mu \mathrm{m})$. The flux prediction errors, along with the errors for the membranes used to develop and validate the model, are given in Table 6 . As expected, the water flux prediction errors for membranes used to develop the model are relatively small $(\leq 11.5 \%)$. However, a relatively large flux prediction error (-23.9\%) for one of the membranes used to validate the model (Membrane A) was observed. This is likely because of the relatively low porosity of this membrane (Table 2). As stated in Section 3.2.1., flux decline would likely occur for a highly compacted membrane and would not be predicted by $C_{m}$. Because a membrane with a low porosity is expected to be structurally similar to a highly compacted membrane, it follows that the flux prediction error using $C_{m}$ for the low porosity membrane is also larger. This suggests the practical limitations of using $C_{m}$ for flux prediction. The model predicts water flux well for the membrane with a large pore size (Membrane D; $0.9 \mu \mathrm{m}$ ) and one of the two membranes with very small pore size (Membrane $\mathrm{G} ; \sim 0.1 \mu \mathrm{m}$ ). The error in flux prediction for Membrane I, which also has a very small pore size $(0.1 \mu \mathrm{m})$, is nearly $60 \%$. It is unclear whether the low porosity $(37.4 \%)$ or the large variation of the experimental water flux $\left( \pm 3 \mathrm{~L} / \mathrm{m}^{2} \mathrm{~h}\right.$, twice the variation observed for other membranes) led to the large predicted flux error for Membrane I. Overall, it appears that the developed model can be used to predict the water flux of membranes with pore sizes from 0.10 to $0.9 \mu \mathrm{m}$, but may not be appropriate for membranes with very low porosities (e.g., Membrane I).

\subsubsection{Performance comparison between the developed model and the simplified dusty gas model}

The flux prediction performance using the simplified dusty gas model with two different $P D_{i j}$ equations is also given in Table 6. Both $P D_{i j}$ equations resulted in similar flux prediction. The simplified dusty gas model (Eq. 4) does not predict flux well for membranes with extremely small pore sizes (Membranes $\mathrm{G}$ and I) or large pore sizes (Membrane D). Because the dusty gas model neglects both surface diffusion and viscous flow when applied to DCMD, only Knudsen diffusion and molecular diffusion are considered as the mass transfer mechanisms. When the membrane pore size is comparable with the mean free path of water vapor in air $(0.11 \mu \mathrm{m}$ [22]), Knudsen diffusion is the dominant mass transfer mechanism. The addition of a molecular diffusion term may result in either over- or under-estimation of water flux depending on membrane properties and experimental conditions (Eq.4). When the membrane pore size is much greater than the mean free path of water vapor in air, molecular diffusion is the dominant mass transfer mechanism. The addition of a Knudsen diffusion term likely led to the over-estimation of water flux for Membrane D $(0.9 \mu \mathrm{m})$. Overall, the model developed using $C_{m}$ has better flux prediction than the dusty gas model and can be used for membranes with a wider range of pore sizes.

\subsection{Model development for the composite membranes}

To investigate whether the membrane constant can be used to predict water flux for composite membranes, nine composite membranes were characterized and studied (Tables 2 and 3). The active layer membrane constant $\left(C_{m a}\right)$ was used to represent the active layer properties since the membrane constant was already validated for single-layer membranes. The support layer properties investigated include support layer membrane constant $\left(C_{m s}\right)$, thickness $\left(\delta_{s}\right)$, tortuosity $\left(\tau_{s}\right)$, porosity $\left(\varepsilon_{s}\right)$, and POSA. Correlation results between composite membrane water flux and the membrane properties are given in Table 7, and it can be seen that none of the membrane properties alone correlate strongly with water flux. Although $C_{m s}$ does not have the highest correlation coefficient with water flux, it's applicability for use with composite membranes alone and in conjunction with $C_{m a}$ is evaluated here. Two linear regression models were tested based on: 1$)$ a single composite membrane property $\left(C_{m a}\right.$ or $\left.C_{m s}\right)$, where the model was expressed the same as Eq. 17; and 2) the mass transfer in series theory, where the model was expressed as:

$$
\frac{1}{\hat{N}_{i}}=b_{0}+b_{1} \frac{1}{C_{m a}}+b_{2} \frac{1}{C_{m s}}
$$

Linear regression tests were performed for both models and the absolute $p$ values were found to be much greater than 0.316. Therefore, a nonlinear relationship exists between water flux and the membrane constant for the composite membranes. One possible reason is the narrow range of experimental water flux; membranes with a wider range of water flux should be tested to continue the model development for the composite membranes. 


\section{Conclusions}

A simplified water flux prediction model was developed to predict the water flux of DCMD membranes. The model uses a newly introduced structural parameter that does not contain coupled properties and can be measured independently while still carrying the physical meaning of a relationship with those membrane properties that may affect water flux (thickness and porosity). Compared to the simplified dusty gas model, the empirical model developed in the current investigation using $C_{m}$ has the following advantages: 1) it can quantitatively analyze water flux with a less complicated expression using uncoupled membrane properties; 2 ) it has better flux prediction and can be used for membranes with a wide range of pore sizes (0.1-0.9 $\mu \mathrm{m})$; and 3) $C_{m}$ characterization can be carried out through simple and reliable measurements using inexpensive analytical equipment. However, using $C_{m}$ for flux prediction does have limitations. It may not be valid for membranes with low porosities and it cannot adequately predict water flux for composite membranes when using the linear regression approach. Future efforts should be made to develop a non-linear prediction model for composite membranes.

\section{Acknowledgments}

The authors would like to thank the U.S. Department of Energy Geothermal Technologies Program (Grant No. DEEE00003231) for the financial support of this work. 


\section{Nomenclature and units}

$b_{(0,1,2)} \quad$ Constants in the regression equation

$B$ Membrane mass transfer coefficient $\left(\mathrm{L} / \mathrm{m}^{2} \mathrm{~Pa} \mathrm{~h}\right)$

$B_{o} \quad$ Membrane geometric factor

$C_{m} \quad$ Membrane constant $\left(\mathrm{m}^{-1}\right)$

$C_{m(a, s)} \quad$ Membrane constant of the active layer $(a)$ or support layer $(s)\left(\mathrm{m}^{-1}\right)$

$d \quad$ Membrane pore size $(\mathrm{m})$

$D_{i j} \quad$ Ordinary diffusion coefficient $\left(\mathrm{m}^{2} / \mathrm{s}\right)$

$h_{m} \quad$ Heat transfer coefficient of the membrane $\left(\mathrm{W} / \mathrm{m}^{2} \mathrm{~K}\right)$

$k_{m} \quad$ Thermal conductivity of the membrane (W/m K)

$K \quad$ Knudsen permeability coefficient $\left(\mathrm{L} / \mathrm{m}^{2} \mathrm{~Pa} \mathrm{~h}\right)$

$l \quad$ Membrane length $(\mathrm{m})$

$m \quad$ Membrane mass (kg)

$M_{(i, j)} \quad$ Molecular weight of vapor $(i)$ or air $(j)(\mathrm{kg} / \mathrm{kmol})$

$n \quad$ Exponent of membrane pore size

$N_{i} \quad$ Overall water flux $\left(\mathrm{L} / \mathrm{m}^{2} \mathrm{~h}\right)$

$N_{(i, j)}^{D} \quad$ Diffusive flux of vapor $(i)$ or air $(j)\left(\mathrm{L} / \mathrm{m}^{2} \mathrm{~h}\right)$

$N_{i}^{V} \quad$ Viscous flux of vapor $\left(\mathrm{L} / \mathrm{m}^{2} \mathrm{~h}\right)$

$\widehat{N}_{i} \quad$ Predicted water flux $\left(\mathrm{L} / \mathrm{m}^{2} \mathrm{~h}\right)$

$p \quad$ Probability of obtaining a test statistic

$P \quad$ Total pressure $(\mathrm{Pa})$

$P_{(i, j, l)} \quad$ Pressure of vapor (i) or air (j) inside the membrane pores or of liquid (l) on the membrane surface (Pa)

$r \quad$ Membrane pore radius (m)

$r_{\max } \quad$ Largest membrane pore radius (m)

$R \quad$ Universal gas constant $(\mathrm{J} / \mathrm{mol} \mathrm{K})$

$T \quad$ Temperature (K)

$T_{m} \quad$ Membrane temperature (K)

$w \quad$ Membrane width (m)

$\beta \quad$ Correlation coefficient

$\gamma_{l} \quad$ Liquid surface tension (Pa m)

$\delta \quad$ Membrane thickness for a single-layer membrane, an active layer or support layer of a composite membrane (m)

$\delta_{\mathrm{s}} \quad$ Support layer thickness $(\mathrm{m})$

$\Delta P \quad$ Total pressure gradient $(\mathrm{Pa})$

$\Delta P_{i} \quad$ Vapor pressure gradient $(\mathrm{Pa})$

$\varepsilon \quad$ Membrane porosity

$\varepsilon_{(a, s)} \quad$ Porosity of the membrane active layer $(a)$ or support layer $(s)$

$\theta \quad$ Contact angle $\left({ }^{\circ}\right)$

$\mu \quad$ Fluid viscosity $(\mathrm{kg} / \mathrm{m} \mathrm{s})$

$\rho_{(m, p)} \quad$ Density of the membrane $(m)$ or membrane polymer $(p)\left(\mathrm{kg} / \mathrm{m}^{3}\right)$

$\tau \quad$ Membrane tortuosity

$\tau_{(a, s)} \quad$ Tortuosity of the membrane active layer $(a)$ or support layer $(s)$ 


\section{Reference}

[1] L.M. Camacho, L. Dumée, J. Zhang, J. Li, M. Duke, J. Gomez, S. Gray, Review: Advances in Membrane Distillation for Water Desalination and Purification Applications, Water, 5 (2013) 94-196.

[2] K.W. Lawson, D.R. Lloyd, Review: Membrane distillation, J. Membr. Sci. , 124 (1997) 1-25.

[3] A.M. Alklaibi, N. Lior, Transport analysis of air-gap membrane distillation, J. Membr. Sci. 255 (2005) $239-253$.

[4] M. Gryta, Concentration of saline wastewater from the production of heparin, Desalination 129, (2000) 35-44.

[5] A. El-Abbassi, A. Hafidi, M.C. García-Payo, M. Khayet, Concentration of olive mill wastewater by membrane distillation for polyphenols recovery, Desalination 245, (2009) 670-674.

[6] P.P. Zolotarev, V.V. Ugrozov, I. B. Volkina, V.M. Nikulin, Treatment of waste water for removing heavy metals by membrane distillation, J. Hazard. Mater., 37 (1994) 77-82.

[7] C.R. Martinetti, A.E. Childress, T.Y. Cath, High recovery of concentrated RO brines using forward osmosis and membrane distillation, J. Membr. Sci., 331 (2009) 31-39.

[8] F. Edwie, T.S. Chung, Development of hollow fiber membranes for water and salt recovery from highly

concentrated brine via direct contact membrane distillation and crystallization, J. Membr. Sci. , 421-422 (2012) 111123.

[9] C. M. Tun, A. G. Fane, J.T. Matheickal, R. Sheikholeslami, Membrane distillation crystallization of concentrated salts-flux and crystal formation, J. Membr. Sci. , 257 (2005) 144-155.

[10] D. Singh, K.K. Sirkar, Desalination of brine and produced water by direct contact membrane distillation at high temperatures and pressures, J. Membr. Sci. , 389 (2012) 380-388.

[11] A. Alkhudhiri, N. Darwish, N. Hilal, Produced water treatment: Application of Air Gap Membrane Distillation, Desalination 309, (2013) 46-51.

[12] K.W. Lawson, D.R. Lloyd, Membrane Distillation. II. Direct contact MD, J. Membr.Sci. , 120 (1996) $123-133$.

[13] K. W. Lawson, D.R. Lloyd, Review: Membrane distillation, J. Membr. Sci. , 124 (1997) 1-25.

[14] J.L. Cartinella, T.Y. Cath, M.T. Flynn, G.C. Miller, K.W. Hunter, A.E. Childress, Removal of natural steroid hormones from wastewater using membrane contactor processes, Environ. Sci. Technol., 40 (2006) 7381-7386.

[15] J.W. D. Hou, C. Zhao, B. Wang, Z. Luan and X. Sun, Fluoride removal from brackish groundwater by direct contact membrane distillation, J. Environ. Sci., 22 (2010) 1860-1867.

[16] S. Yarlagadda, V.G. Gude, L.M. Camacho, S. Pinappu, S. Deng, Potable water recovery from As, U, and F contaminated ground waters by direct contact membrane distillation process, J. Hazard. Mater., 192 (2011) 13881394.

[17] T.Y. Cath, V.D. Adams, A.E. Childress, Membrane contactor processes for wastewater reclamation in space. II. Combined direct osmosis, osmotic distillation, and membrane distillation for treatment of metabolic wastewater, J. Membr. Sci., 257 (2005) 111-119.

[18] A.O. Imdakm, T. Matsuura, Simulation of heat and mass transfer in direct contact membrane distillation (MD): The effect of membrane physical properties, Journal of Membrane Science 262 (2005) 117-128.

[19] R.W. Schofield, A.G. Fane, C.J.D. Fell, Heat and mass transfer in membrane distillation, J. Membr. Sci., 33 (1987) 299-313.

[20] L. Mart'inez-D'iez, M.I. Vázquez-González, A method to evaluate coefficients affecting flux in membrane distillation, Journal of Membrane Science, 173 (2000) 225-234.

[21] A.O. Imdakm, T. Matsuura, A Monte Carlo simulation model for membrane distillation processes: direct contact (MD), J. Membr. Sci., 237 (2004) 51-59.

[22] J. Phattaranawik, R. Jiraratananon, A.G. Fane, Effect of pore size distribution and air flux on mass transport in direct contact membrane distillation, J. Membr. Sci., 215 (2003) 75-85.

[23] S. Srisurichan, R. Jiraratananon, A.G. Fane, Mass transfer mechanisms and transport resistances in direct contact membrane distillation process, J. Membr. Sci., 277 (2006) 186-194.

[24] M. Qtaishat, T. Matsuura, B. Kruczek, M. Khayet, Heat and mass transfer analysis in direct contact membrane distillation, Desalination 219, (2008) 272-292.

[25] A.R.D. Costa, A.G. Fane, D.E. Wiley, Spacer characterization and pressure drop modelling in spacer-filled channels for ultrafiltration, J. Membr. Sci., 87 (1994) 79-98.

[26] J. Phattaranawik, R. Jiraratananon, A.G. Fane, C. Halim, Mass flux enhancement using spacer filled channels in direct contact membrane distillation, J. Membr. Sci., 187 (2001) 193-201.

[27] L. Martínez, J.M. Rodríguez-Maroto, Characterization of membrane distillation modules and analysis of mass flux enhancement by channel spacers, J. Membr. Sci., 274 (2006) 123-137.

[28] T.Y. Cath, V.D. Adams, A.E. Childress, Experimental study of desalination using direct contact membrane distillation: a new approach to flux enhancement, J. Membr.Sci., 228 (2004) 5-16. 
[29] J. Zhang, J. D. Li, S. Gray, Effect of applied pressure on performance of PTFE membrane in DCMD J. Membr. Sci., 369 (2011) 514-525.

[30] Z. Ding, R. Ma, A.G. Fane, A new model for mass transfer in direct contact membrane distillation, Desalination 151, (2002) 217-227.

[31] A. Hernfindez, J.I. Calvo, P. Prfidanos, F. Tejerina, Pore size distributions in microporous membranes: A critical analysis of the bubble point extended method, J. Membr. Sci., 112 (1996) 1-12.

[32] J. Woods, J. Pellegrino, J. Burch, Generalized guidance for considering pore-size distribution in membrane distillation, J. Membr. Sci., 368 (2011) 124-133.

[33] S. Bonyadi, T.S. Chung, Flux enhancement in membrane distillation by fabrication of dual layer hydrophilichydrophobic hollow fiber membranes, J. Membr. Sci., 306 (2007) 134-146.

[34] L. Martínez, J.M. Rodríguez-Maroto, Membrane thickness reduction effects on direct contact membrane distillation performance, J. Membr. Sci., 312 (2008) 143-156.

[35] J. Zhang, N. Dow, M. Duke, E. Ostarcevic, J. Li, S. Gray, Identification of material and physical features of membrane distillation membranes for high performance desalination, J. Membr. Sci. , 349 (2010) 295-303.

[36] M. I. Ali, E. K. Summers, H. A. Arafat, J.H. LienhardV, Effects of membrane properties on water production cost in small scale membrane distillation systems, Desalination 306, (2012) 60-71.

[37] K.W. Lawson, M.S. Hall, D.R. Lloyd, Compaction of microporous membranes used in membrane distillation. I. Effect on gas permeability, J. Membr. Sci., 101 (1995) 99-108.

[38] M.S. El-Bourawi, Z. Ding, R. Ma, M. Khayet, A framework for better understanding membrane distillation separation process, J. Membr. Sci., 285 (2006) 4-29.

[39] A. Alkhudhiri, N. Darwish, N. Hilal, Membrane distillation: A comprehensive review, Desalination 287, (2012) $2-18$.

[40] J. Mericq, S. Laborie, C. Cabassud, Vacuum membrane distillation of seawater reverse osmosis brines, Water Res., 44 (2010) 5260-5273.

[41] D. Hou, G. Dai, J. Wang, H. Fan, L. Zhang, Z. Luan, Preparation and characterization of PVDF/nonwoven fabric flat-sheet composite membranes for desalination through direct contact membrane distillation, Sep. Purif. Technol. 101, (2012) 1-10.

[42] B.S. Lalia, E. Guillen-Burrieza, H.A. Arafat, R. Hashaikeh, Fabrication and characterization of polyvinylidenefluoride-co-hexafluoropropylene (PVDF-HFP) electrospun membranes for direct contact membrane distillation J. Membr. Sci. , 428 (2013) 104-115.

[43] S. B. Iversen, V. K. Bhatia, K .Dam-Johansen, G. Jonsson, Characterization of microporous membranes for use in membrane contactors, J. Membr. Sci., 130 (1997) 205-217.

[44] C. Fernández-Pineda, M.A. Izquierdo-Gil, M.C. Garcia-Payo, Gas permeation and direct contact membrane distillation experiments and their analysis using different models, J. Membr. Sci., 198 (2002) 33-49.

[45] J. Phattaranawik, R. Jiraratananon, A.G. Fane, Heat transport and membrane distillation coefficients in direct contact membrane distillation, J. Membr. Sci., 212 (2003) 177-193.

[46] M. Khayet, K.C. Khulbe, T. Matsuurab, Characterization of membranes for membrane distillation by atomic force microscopy and estimation of their water vapor transfer coefficients in vacuum membrane distillation process J. Membr. Sci., 238 (2004) 199-211.

[47] M. Khayet, Membranes and theoretical modeling of membrane distillation: A review, Adv. Colloid Interface Sci., 164 (2011) 56-88.

[48] F.K. Smolders, Terminology for Membrane Distillation, Desalination 72, (1989) 249-262.

[49] Q. Huang, C. Xiao, X. Hu, X. Li, Study on the effects and properties of hydrophobic poly(tetrafluoroethylene) membrane, Desalination 277, (2011) 187-192.

[50] S. Nakao, Review: Determination of pore size and pore size distribution 3. Filtration membranes, J. Membr. Sci., 96 (1994) 131-165.

[51] M. Khayet, T. Matsuura, Determination of surface and bulk pore sizes of flat-sheet and hollow-fiber membranes by atomic force microscopy, gas permeation and solute transport methods, Desalination 158, (2003) 5764.

[52] H.Yasuda, J.T.Tsai, Pore size of microporous polymer membranes, J. Appl. Polym. Sci., 18 (1974) $805-819$.

[53] R. Mishra, S.P. Tripathy, D. Sinha, K.K. Dwivedi, S. Ghosh, D.T. Khathing, M. Muller, D. Fink, W.H. Chung, Optical and electrical properties of some electron and proton irradiated polymers, Nucl. Instrum. Methods Phys. Res., Sect. B 168, (2000) 59-64.

[54] Y. Luo, Y. Liu, Q. Yu, Influence of glow discharge plasma treatment on vapor-induced response of poly(vinylidene fluoride)-carbon black composite thin films, Thin Solid Films 515, (2007) 4016-4023. 
[55] M. Mulder, Basic principles of membrane technology, Kluver Academic Publishers, Dordrecht, Netherlands, 1991.

[56] J. A. Ruskowitz, A.E. Childress, Salt-Gradient Solar Pond and Membrane Distillation System for Water Desalination Powered by Renewable Energy, in: Thesis, University of Nevada, Reno, Reno, Nevada, 2012. [57] V.D. Alves, I.M. Coelhoso, Effect of membrane characteristics on mass and heat transfer in the osmotic evaporation process, J. Membr. Sci., 228 (2004) 159-167.

[58] S. Adnan, M. Hoang, H. Wang, Z. Xie, Commercial PTFE membranes for membrane distillation application: Effect of microstructure and support material, Desalination 284, (2012) 297-308.

[59] F. Meng, H. Zhang, F. Yang, S. Zhang, Y. Li, X. Zhang, Identification of activated sludge properties affecting membrane fouling in submerged membrane bioreactors, Sep. Purif. Technol., 51 (2006) 95-103.

[60] J.A. Brant, A.E. Childress, Assessing short-range membrane-colloid interactions using surface energetics, J. Membr. Sci., 203 (2002) 257-273.

[61] P.C. Carman, Flow of Gases Through Porous Media, Butterworth Scientific Publications, London, UK, 1956.

[62] M.H.Kutner, C.J.Nachtsheim, J. Neter, Applied Linear Regression Models 4th ed., McGraw-Hill/Irwin, New York, U.S.A, 2004.

[63] J. W. Stephens, J. A. Unruh, M. E. Dikeman, M. C. Hunt, T. E. Lawrence, T. M.Loughin, Mechanical probes can predict tenderness of cooked beef longissimus using uncooked measurements, J. Anim. Sci., 82 (2004) 20772086.

[64] R.L. Ott, M. Longnecker, An introduction to statistical methods and data analysis, fifth ed., Duxbury, California, 2001.

[65] A.M. Alklaibi, N. Lior, Membrane-distillation desalination: status and potential, Desalination, 171 (2004) 111131.

[66] M. C. Garc ía-Payo, M. A. Izquierdo-Gil, C.F. ández-Pineda, Wetting Study of Hydrophobic Membranes via Liquid Entry Pressure Measurements with Aqueous Alcohol Solutions, J. Colloid Interface Sci., 230 (2000) 420-431. [67] F. A. Banat, J. Simandl, Theoretical and experimental study in membrane distillation, Desalination 95, (1994) 39-52.

[68] A.M. Barbe, P.A. Hogan, R.A. Johnson, Surface morphology changes during initial usage of hydrophobic, microporous polypropylene membranes, J. Membr.Sci. , 172 (2000) 149-156.

[69] M. Gryta, Long-term performance of membrane distillation process, J. Membr.Sci., 265 (2005) 153-159.

[70] S. K, W. Hölz, R. Wollbeck, Membranes and modules for transmembrane distillation, J. Membr. Sci., 39(1)

(1988) 25-42. 


\section{List of Tables}

Table 1: Membrane properties as reported by manufacturers. PTFE - polytetrafluorethylene; PP - polypropylene; PVDF - polyvinylidene fluoride.

Table 2: Properties of single-layer membranes, composite membrane active layers, and intact membrane fluxes.

Table 3: Properties of composite membrane support layers. A tortuosity of 1 is assumed for the scrim support layers [59].

Table 4: Correlation results between water flux and membrane structural parameters for single-layer membranes. Bold numbers indicate the structural parameters with the highest correlations with water flux.

Table 5: Regression results for candidate models based on the model development and validation data sets. The structural parameters all have units of $1 / \mu \mathrm{m}$.

Table 6: Flux prediction error (\%) between the measured water fluxes and the predicted water fluxes.

Table 7: Correlation results between water flux and membrane structural parameters for composite membranes. 
Table 1: Membrane properties as reported by manufacturers. PTFE - polytetrafluorethylene; PP - polypropylene; PVDF - polyvinylidene fluoride.

\begin{tabular}{cccccc}
\hline Membrane & $\begin{array}{c}\text { Nominal pore } \\
\text { size }(\mu \mathrm{m})\end{array}$ & $\begin{array}{c}\text { Thickness }^{\mathrm{a}} \\
(\mu \mathrm{m})\end{array}$ & $\begin{array}{c}\text { Porosity } \\
(\%)\end{array}$ & $\begin{array}{c}\text { Active layer } \\
\text { material }\end{array}$ & $\begin{array}{c}\text { Support layer } \\
\text { material }\end{array}$ \\
\hline A & 0.20 & 79 & 70 & PTFE & -- \\
B & 0.22 & -- & -- & PTFE & -- \\
C & 0.22 & -- & - & PP & -- \\
D & 0.80 & 75 & 76 & PTFE & -- \\
E & 0.20 & 80 & 74 & PTFE & -- \\
F & 0.10 & $76-154$ & -- & PTFE & -- \\
G & 0.10 & -- & -- & PTFE & -- \\
H & 0.50 & 75 & 78 & PTFE & -- \\
I & 0.10 & 70 & 68 & PTFE & -- \\
J & 0.45 & -- & 83 & PVDF & -- \\
\hline K & 0.45 & -- & -- & PTFE & PP \\
L & 0.45 & 195 & -- & PTFE & PP \\
M & 0.20 & 192 & -- & PTFE & PP \\
N & 0.45 & 279 & -- & PTFE & PP \\
O & 0.20 & -- & -- & PTFE & PP \\
P & 0.20 & -- & -- & PTFE & PP \\
Q & 0.20 & 130 & $72^{\mathrm{b}}$ & PTFE & PP \\
R & 0.50 & 120 & $74^{\mathrm{b}}$ & PTFE & PP \\
S & 0.45 & 190 & -- & PTFE & PP \\
\hline
\end{tabular}

${ }^{a}$ sum of the active layer thickness and support layer thickness for composite membranes

${ }^{\mathrm{b}}$ refers to the percent open area of the membrane 
Table 2: Properties of single-layer membranes, composite membrane active layers, and intact membrane fluxes.

\begin{tabular}{cccccccc}
\hline Membrane & $\begin{array}{c}\text { Pore size } \\
(\mu \mathrm{m})\end{array}$ & $\begin{array}{c}\text { Porosity }^{\mathrm{b}}(\%) \\
(\%\end{array}$ & Tortuosity $^{\mathrm{b}}$ & $\begin{array}{c}\text { Thickness } \\
(\mu \mathrm{m})\end{array}$ & $\begin{array}{c}\text { Contact } \\
\text { angle }\left({ }^{\circ}\right)\end{array}$ & $\begin{array}{c}\text { Liquid entry } \\
\text { pressure } \\
(\mathrm{kPa})\end{array}$ & $\begin{array}{c}\text { Flux }^{\mathrm{c}} \\
\left(\mathrm{L} / \mathrm{m}^{2} \mathrm{~h}\right)\end{array}$ \\
\hline $\mathrm{A}$ & $0.22 \pm 0.11$ & 53.4 & 4.02 & $39 \pm 5$ & $125 \pm 2$ & $380 \pm 4$ & $28.7 \pm 0.9$ \\
$\mathrm{~B}$ & $0.25 \pm 0.06$ & 84.5 & 1.58 & $119 \pm 11$ & $128 \pm 3$ & $430 \pm 5$ & $25.8 \pm 0.5$ \\
$\mathrm{C}$ & $0.24 \pm 0.13$ & 82.6 & 1.67 & $205 \pm 4$ & $126 \pm 1$ & $375 \pm 3$ & $21.3 \pm 0.7$ \\
$\mathrm{D}$ & $0.90 \pm 0.09$ & 78.8 & 1.86 & $78 \pm 2$ & $121 \pm 2$ & $141 \pm 5$ & $26.8 \pm 1.5$ \\
$\mathrm{E}$ & $0.25 \pm 0.06$ & 67.4 & 2.61 & $95 \pm 3$ & $114 \pm 3$ & $258 \pm 5$ & $18.3 \pm 1.1$ \\
$\mathrm{~F}$ & $0.18 \pm 0.02$ & 80.1 & 1.79 & $67 \pm 17$ & $131 \pm 3$ & $385 \pm 3$ & $34.5 \pm 1.2$ \\
$\mathrm{G}$ & $0.11 \pm 0.05$ & 84.1 & 1.60 & $111 \pm 4$ & $124 \pm 3$ & $358 \pm 6$ & $17.5 \pm 0.3$ \\
$\mathrm{H}$ & $0.36 \pm 0.04$ & 61.2 & 3.15 & $56 \pm 4$ & $109 \pm 4$ & $183 \pm 5$ & $21.9 \pm 1.2$ \\
$\mathrm{I}$ & $0.10 \pm 0.01$ & 37.4 & 7.07 & $63 \pm 4$ & $114 \pm 2$ & $400 \pm 10$ & $11.4 \pm 3.0$ \\
$\mathrm{~J}$ & $0.51 \pm 0.04$ & 65.2 & 2.79 & $109 \pm 6$ & $118 \pm 3$ & $154 \pm 6$ & $24.3 \pm 1.1$ \\
\hline $\mathrm{K}^{a}$ & $0.34 \pm 0.19$ & 56.1 & 3.68 & $31 \pm 5$ & $120 \pm 5$ & $415 \pm 10$ & $28.1 \pm 0.3$ \\
$\mathrm{~L}^{a}$ & $0.52 \pm 0.08$ & 84.2 & 1.59 & $27 \pm 2$ & $118 \pm 5$ & $190 \pm 5$ & $26.0 \pm 1.1$ \\
$\mathrm{M}^{\mathrm{a}}$ & $0.19 \pm 0.11$ & 46.6 & 5.05 & $31 \pm 4$ & $106 \pm 6$ & $290 \pm 5$ & $25.3 \pm 1.2$ \\
$\mathrm{~N}^{a}$ & $0.57 \pm 0.26$ & 90.3 & 1.33 & $59 \pm 3$ & $126 \pm 1$ & $95 \pm 6$ & $26.3 \pm 0.6$ \\
$\mathrm{O}^{a}$ & $0.23 \pm 0.04$ & 81.1 & 1.74 & $58 \pm 18$ & $125 \pm 2$ & $380 \pm 5$ & $24.5 \pm 1.0$ \\
$\mathrm{P}^{a}$ & $0.25 \pm 0.01$ & 79.6 & 1.82 & $50 \pm 11$ & $125 \pm 3$ & $395 \pm 10$ & $24.0 \pm 0.9$ \\
$\mathrm{Q}^{a}$ & $0.21 \pm 0.04$ & 64.4 & 2.85 & $31 \pm 10$ & $128 \pm 2$ & $390 \pm 15$ & $25.7 \pm 1.1$ \\
$\mathrm{R}^{a}$ & $0.50 \pm 0.15$ & 71.3 & 2.32 & $47 \pm 4$ & $120 \pm 2$ & $438 \pm 5$ & $25.8 \pm 0.2$ \\
$\mathrm{~S}^{a}$ & $0.44 \pm 0.13$ & 77.5 & 1.94 & $21 \pm 3$ & $109 \pm 2$ & $238 \pm 15$ & $22.2 \pm 3.5$ \\
\hline
\end{tabular}

${ }^{a}$ active layer of the composite membrane

${ }^{\mathrm{b}}$ calculated using the average membrane properties

${ }^{\mathrm{c}}$ refers to the intact membrane flux 
Table 3: Properties of composite membrane support layers. A tortuosity of 1 is assumed for the scrim support layers [59].

\begin{tabular}{cccccc}
\hline Membrane & $\begin{array}{c}\text { Membrane } \\
\text { structure }\end{array}$ & $\begin{array}{c}\text { Porosity }^{\mathrm{a}} \\
(\%)\end{array}$ & Tortuosity $^{\mathrm{a}}$ & $\begin{array}{c}\text { Thickness } \\
(\mu \mathrm{m})\end{array}$ & $\begin{array}{c}\text { POSA } \\
(\%)\end{array}$ \\
\hline $\mathrm{K}^{s}$ & Scrim & 58.6 & 1 & $77 \pm 14$ & 43.2 \\
$\mathrm{~L}^{s}$ & Non-woven & 72.8 & 1.37 & $283 \pm 9$ & 3.76 \\
$\mathrm{M}^{s}$ & Non-woven & 80.9 & 1.20 & $171 \pm 8$ & 4.09 \\
$\mathrm{~N}^{s}$ & Non-woven & 70.6 & 1.42 & $230 \pm 10$ & 3.97 \\
$\mathrm{O}^{s}$ & Scrim & 52.0 & 1 & $255 \pm 14$ & 44.6 \\
$\mathrm{P}^{s}$ & Non-woven & 72.3 & 1.38 & $194 \pm 13$ & 11.4 \\
$\mathrm{Q}^{s}$ & Scrim & 39.4 & 1 & $54 \pm 7$ & 35.4 \\
$\mathrm{R}^{s}$ & Scrim & 30.5 & 1 & $50 \pm 6$ & 37.4 \\
$\mathrm{~S}^{s}$ & Non-woven & 65.5 & 1.53 & $133 \pm 11$ & 3.21 \\
\hline
\end{tabular}

${ }^{s}$ support layer of the composite membrane

${ }^{a}$ calculated using the average membrane properties 
Table 4: Correlation results between water flux and membrane structural parameters for single-layer membranes. Bold numbers indicate the structural parameters with the highest correlations with water flux.

\begin{tabular}{ccc}
\hline & $\begin{array}{c}\text { Structural } \\
\text { parameter }\end{array}$ & $\begin{array}{c}\text { Correlation } \\
\text { coefficient }\end{array}$ \\
\hline & $\varepsilon / \tau \delta$ & $\mathbf{0 . 7 3 1}$ \\
& $r \varepsilon / \tau \delta$ & 0.399 \\
& $r^{2} \varepsilon / \tau \delta$ & 0.251 \\
& $\varepsilon / \tau$ & 0.326 \\
Structural parameters & $r \varepsilon / \tau$ & 0.336 \\
reported in literature & $r^{2} \varepsilon / \tau$ & 0.243 \\
& $1 / \tau \delta$ & $\mathbf{0 . 7 8 1}$ \\
& $r$ & 0.303 \\
& $\varepsilon$ & 0.428 \\
& $1 / \delta$ & 0.243 \\
\hline & $1 / \tau$ & 0.357 \\
Basic membrane & $1 / L E P$ & 0.111 \\
properties & $1 / k_{m}$ & 0.168 \\
& $1 / h_{m}$ & -0.080 \\
\hline & $r \varepsilon / \delta$ & 0.402 \\
& $r^{2} \varepsilon / \delta$ & 0.257 \\
& $\varepsilon / \delta$ & $\mathbf{0 . 6 3 8}$ \\
& $r^{2} \varepsilon$ & 0.244 \\
& $r \varepsilon$ & 0.329 \\
Other structural & $r^{2} / \delta$ & 0.261 \\
parameters & $r / \delta$ & 0.376 \\
& $r / \tau \delta$ & 0.405 \\
& $r^{2} / \tau \delta$ & 0.253 \\
& $r / \tau$ & 0.336 \\
& $r^{2} / \tau$ & 0.244 \\
& $r^{2}$ & 0.243 \\
\hline pew structural & $C_{m}$ & $\mathbf{0 . 7 1 4}$ \\
\hline & &
\end{tabular}


Table 5: Regression results for candidate models based on the model development and validation data sets. The structural parameters all have units of $1 / \mu \mathrm{m}$.

\begin{tabular}{c|ccc|ccc|ccc}
\hline \multirow{2}{*}{ Statistics } & \multicolumn{3}{|c|}{ Test 1 } & \multicolumn{3}{c|}{ Test 2 } & \multicolumn{3}{c}{ Test 3 } \\
& $C_{m} \times 10^{3}$ & $\varepsilon / \tau \delta \times 10^{4}$ & $1 / \tau \delta \times 10^{4}$ & $C_{m} \times 10^{3}$ & $\varepsilon / \tau \delta \times 10^{4}$ & $1 / \tau \delta \times 10^{4}$ & $C_{m} \times 10^{3}$ & $\varepsilon / \tau \delta \times 10^{4}$ & $1 / \tau \delta \times 10^{4}$ \\
\hline $\mathrm{p}$ & 0.053 & 0.062 & 0.073 & 0.010 & 0.052 & 0.019 & 0.079 & 0.058 & 0.102 \\
$\mathrm{~b}_{0}$ & 15.13 & 16.60 & 15.10 & 10.10 & 13.04 & 10.41 & 12.67 & 13.46 & 11.53 \\
$\mathrm{~s}\left\{\mathrm{~b}_{0}\right\}$ & 3.802 & 3.593 & 4.348 & 2.863 & 4.363 & 3.513 & 4.991 & 4.147 & 6.054 \\
$\mathrm{~b}_{1}$ & 0.239 & 0.263 & 0.208 & 0.318 & 0.323 & 0.285 & 0.262 & 0.295 & 0.252 \\
$\mathrm{~s}\left\{\mathrm{~b}_{1}\right\}$ & 0.077 & 0.091 & 0.077 & 0.006 & 0.103 & 0.061 & 0.100 & 0.099 & 0.108 \\
$\mathrm{SSE}$ & 28.87 & 31.96 & 35.27 & 13.36 & 37.75 & 19.83 & 44.50 & 36.76 & 52.13 \\
PRESS & 81.69 & 73.41 & 92.87 & 39.92 & 69.61 & 62.18 & 183.8 & 145.9 & 227.7 \\
MSE & 9.622 & 10.65 & 11.76 & 4.450 & 12.58 & 6.610 & 14.83 & 12.25 & 17.38 \\
MSPR & 13.01 & 18.57 & 13.60 & 20.71 & 12.16 & 21.19 & 2.031 & 13.83 & 3.450 \\
MSPR:MSE & 1.352 & 1.744 & 1.156 & 4.654 & 0.967 & 3.206 & 0.137 & 1.129 & 0.198 \\
Adjusted R & $68.4 \%$ & $65.0 \%$ & $61.4 \%$ & $89.0 \%$ & $68.8 \%$ & $83.6 \%$ & $59.5 \%$ & $66.5 \%$ & $52.5 \%$ \\
\hline
\end{tabular}


Table 6: Flux prediction error (\%) between the measured water fluxes and the predicted water fluxes.

\begin{tabular}{c|c|c|c|c}
\hline & Membrane & $\begin{array}{c}\text { Current model } \\
(\%)\end{array}$ & $\begin{array}{c}\text { Dusty gas }^{\mathrm{a}} \\
\text { model v.1 }^{\mathrm{b}}(\%)\end{array}$ & $\begin{array}{c}\text { Dusty gas } \\
\text { model v.2 }^{\mathrm{c}}(\%)\end{array}$ \\
\hline \multirow{3}{*}{ Model development } & $\mathrm{B}$ & 5.97 & 48.2 & 42.8 \\
& $\mathrm{C}$ & -10.6 & -2.61 & -6.13 \\
& $\mathrm{E}$ & 11.5 & 28.0 & 23.4 \\
& $\mathrm{~F}$ & -1.59 & 36.9 & 32.5 \\
\multirow{2}{*}{ Model validation } & $\mathrm{J}$ & -3.84 & -7.05 & -11.2 \\
\hline \multirow{2}{*}{ Pore size near $0.1 \mu \mathrm{m}$} & $\mathrm{A}$ & -23.9 & -2.50 & -5.86 \\
\hline Pore size of $0.9 \mu \mathrm{m}$ & $\mathrm{H}$ & 12.6 & 50.9 & 44.6 \\
\hline
\end{tabular}

${ }^{\mathrm{a}}$ Eq. 18

${ }^{\text {b Eq. }} 6$ was used for $P D_{i j}$ in Eq. 4 for flux prediction

${ }^{\mathrm{c}}$ Eq. 7 was used for $P D_{i j}$ in Eq. 4 for flux prediction 
Table 7: Correlation results between water flux and membrane structural parameters for composite membranes.

\begin{tabular}{cc}
\hline Membrane property & Correlation coefficient \\
\hline$C_{m a}$ & -0.316 \\
$1 / \delta_{s}$ & 0.309 \\
$\mathcal{E}_{s}$ & -0.165 \\
$1 / \tau_{s}$ & 0.496 \\
$C_{m s}$ & 0.318 \\
POSA & 0.448 \\
\hline
\end{tabular}




\section{List of Figures}

Figure 1: Thermal circuit of the dusty gas model [13].

Figure 2: Schematic drawing of bench-scale DCMD system. The arrows in the membrane module indicate the direction of water vapor passing through the membrane.

Figure 3: SEM images of (a) scrim support layer and (b) non-woven support layer. 


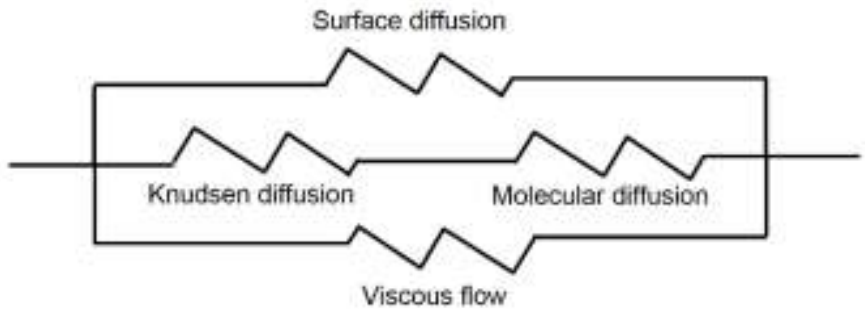

Figure 1: Thermal circuit of the dusty gas model [13]. 


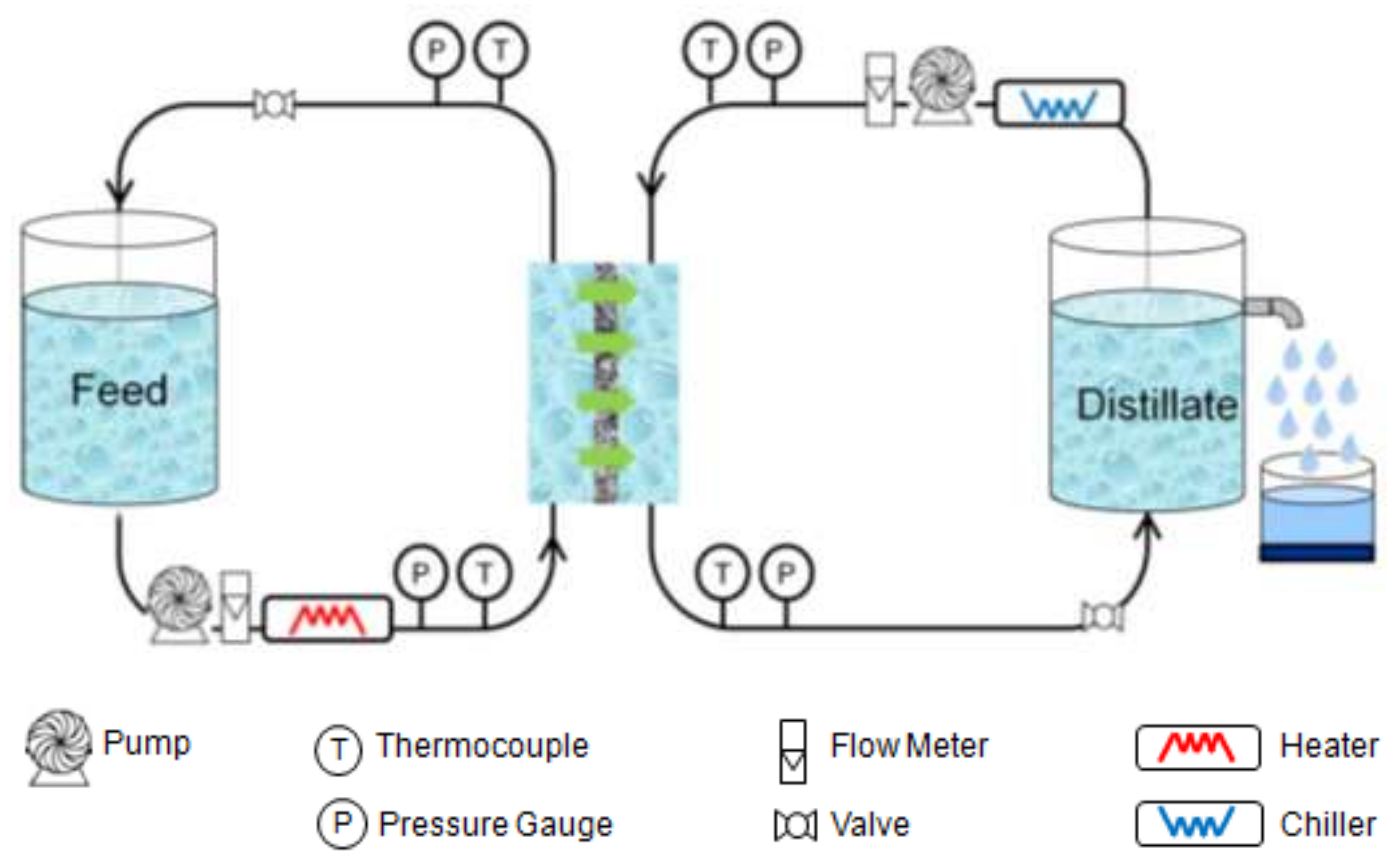

Figure 2: Schematic drawing of bench-scale DCMD system. The arrows in the membrane module indicate the direction of water vapor passing through the membrane. 


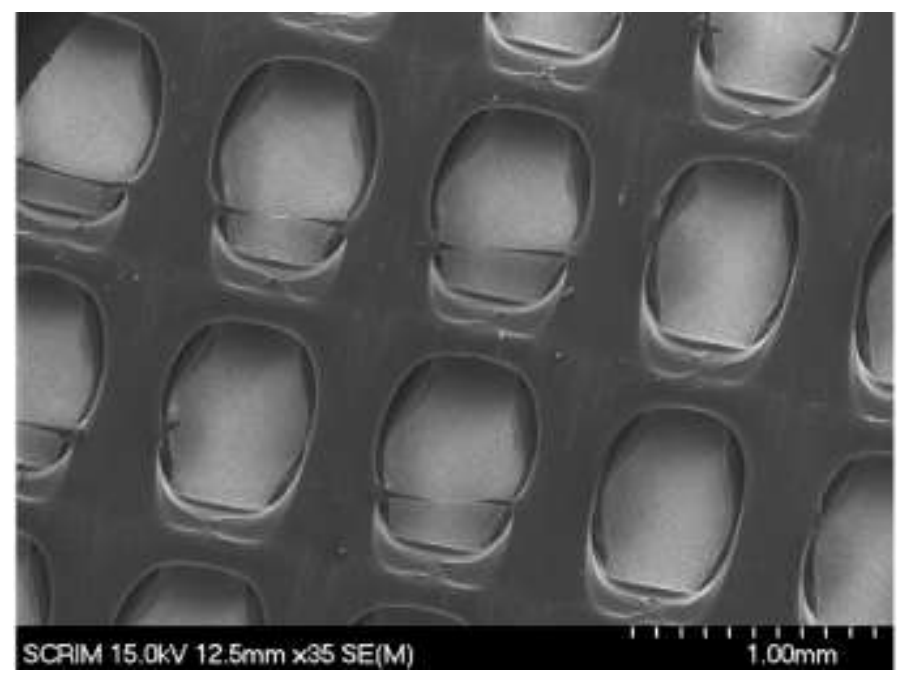

(a)

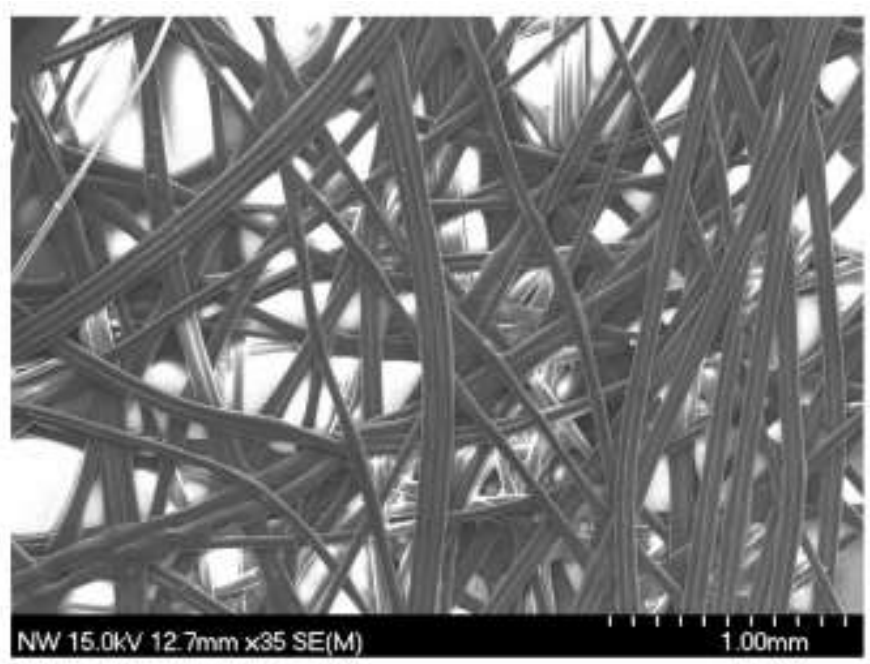

(b)

Figure 3: SEM images of (a) scrim support layer and (b) non-woven support layer. 


\section{List of Appendices}

Appendix A: Scatterplots of water flux vs. membrane structural parameters for single-layer membranes used to identify the structural parameters that correlate well with water flux.

Appendix B: Residual plots used to validate the assumptions of the linear regression analysis. 
Appendix A: Scatterplots of water flux vs. membrane structural parameters for single-layer membranes used to identify the structural parameters that correlate well with water flux.

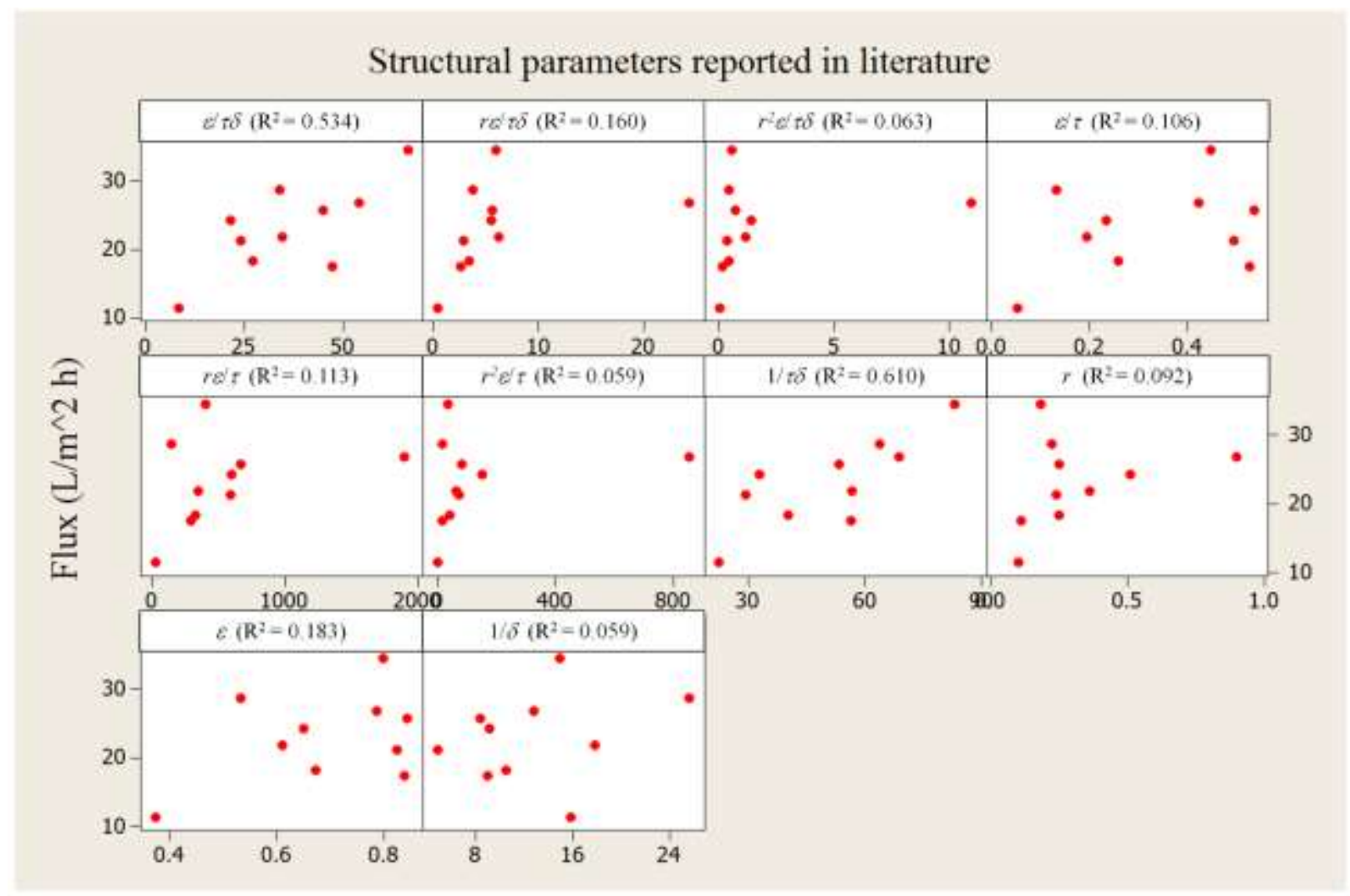



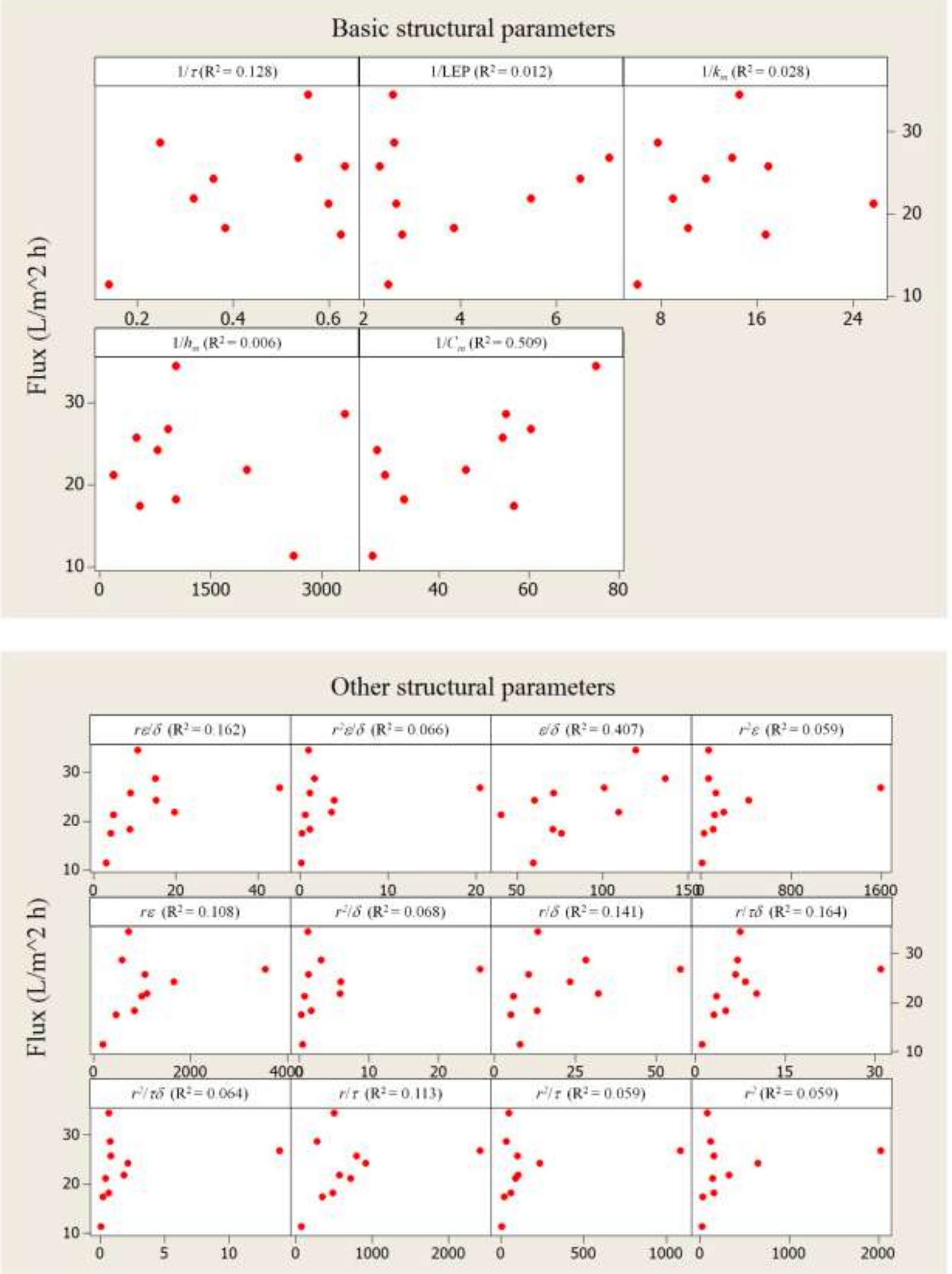
Appendix B: Residual plots used to validate the assumptions of the linear regression analysis.

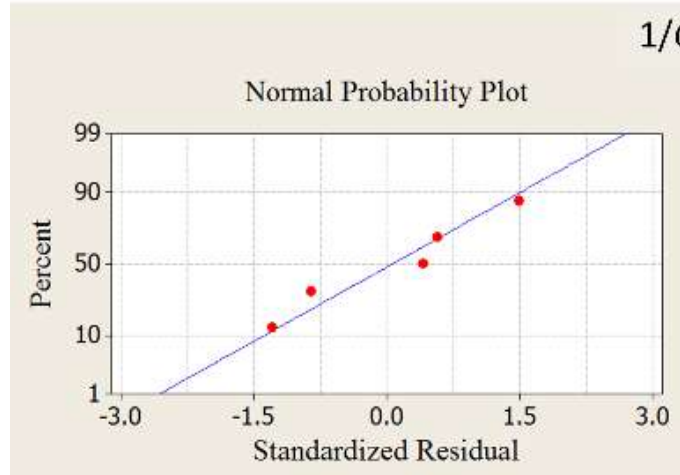

$$
1 / C_{m}
$$
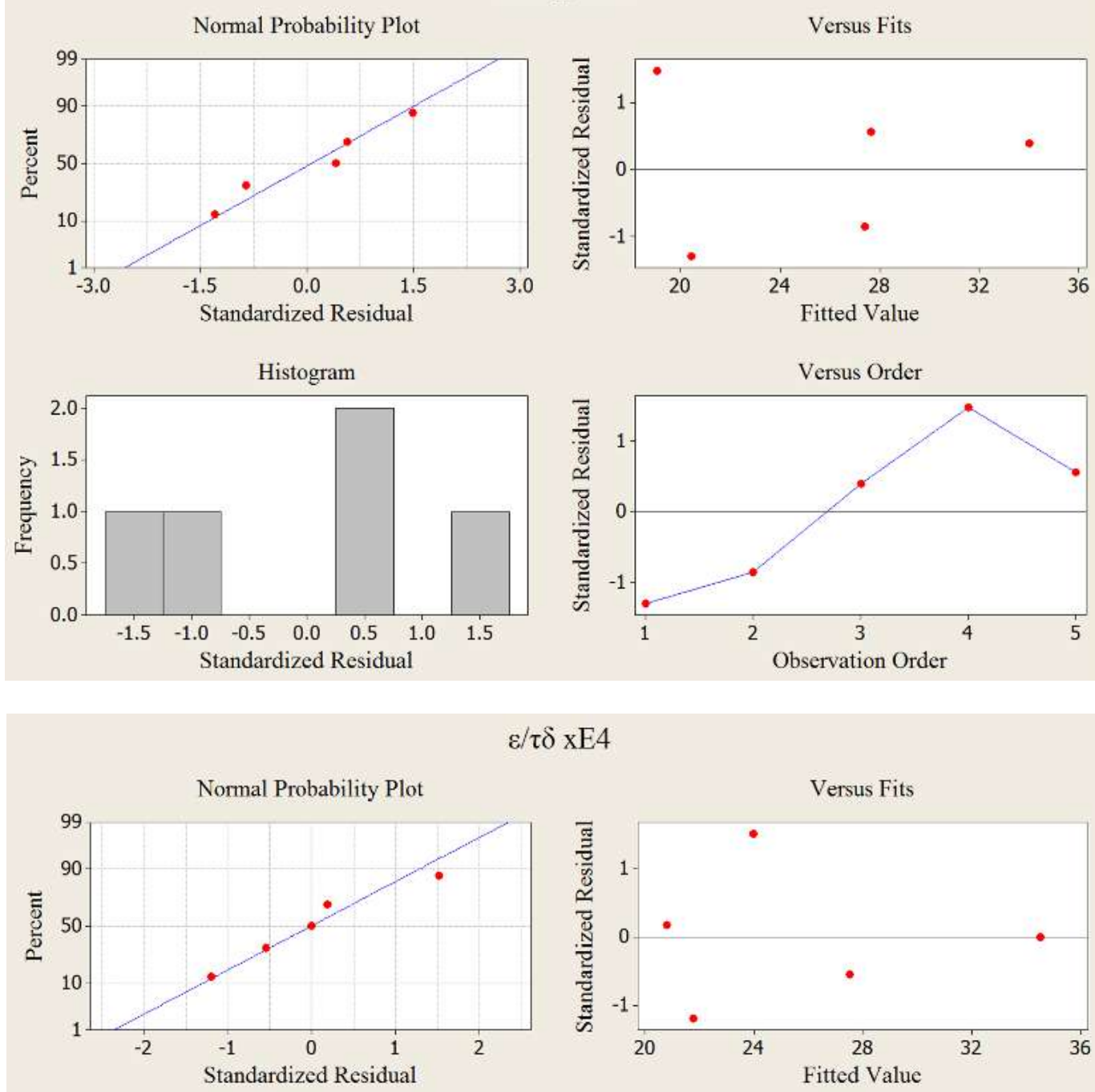

$\varepsilon / \tau \delta \times \mathrm{xE} 4$
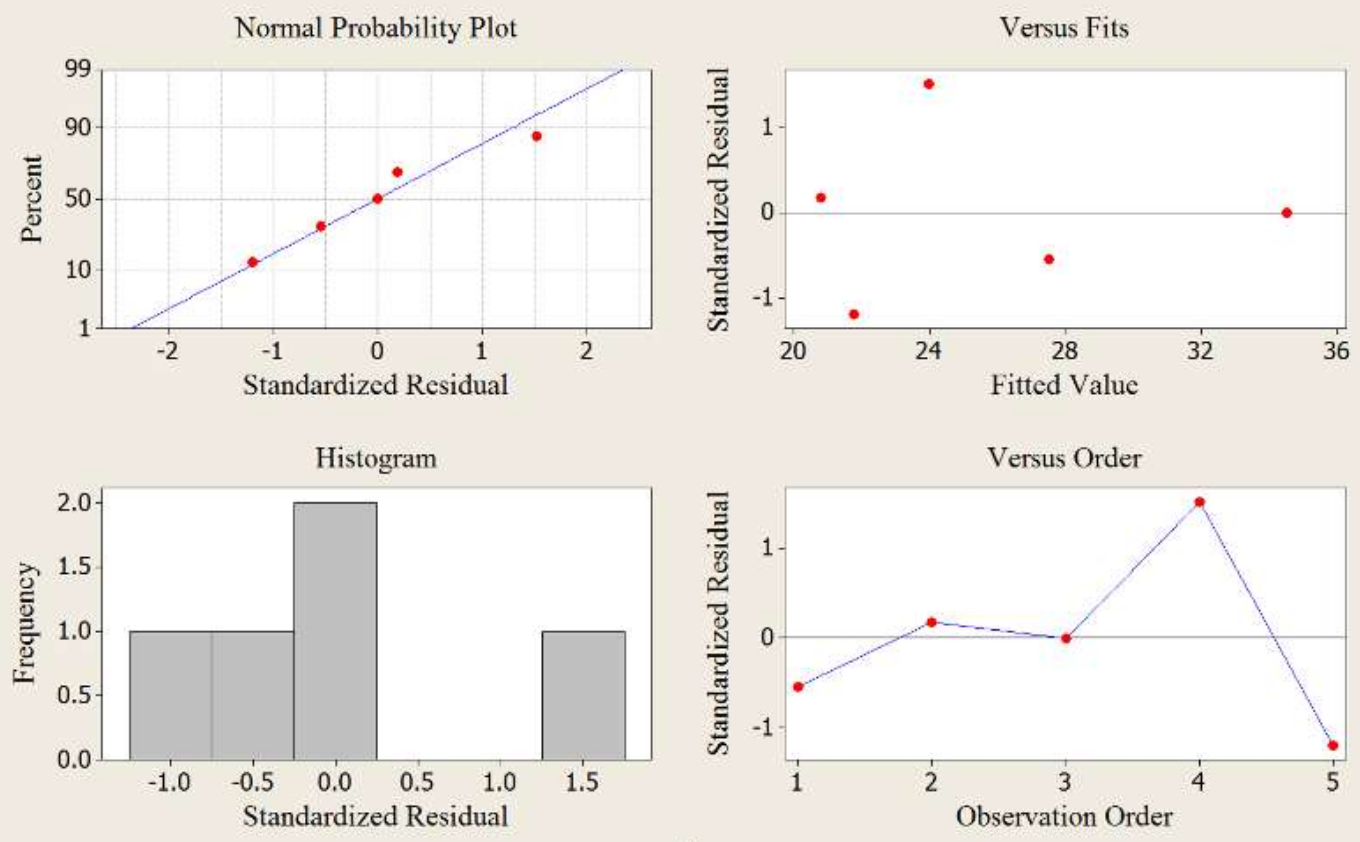


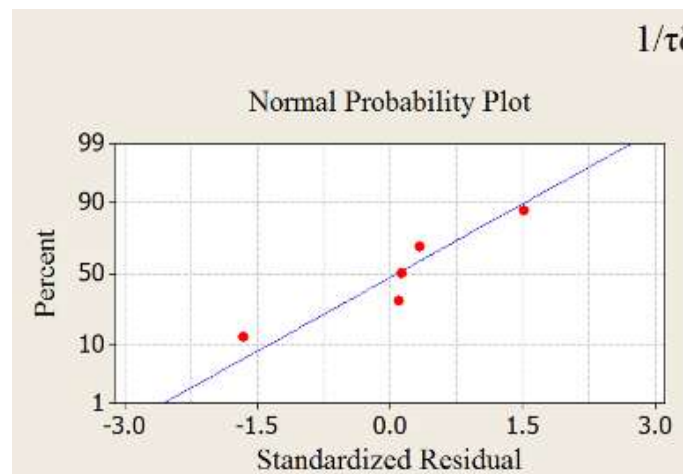

$1 / \tau \delta \mathrm{xE} 4$
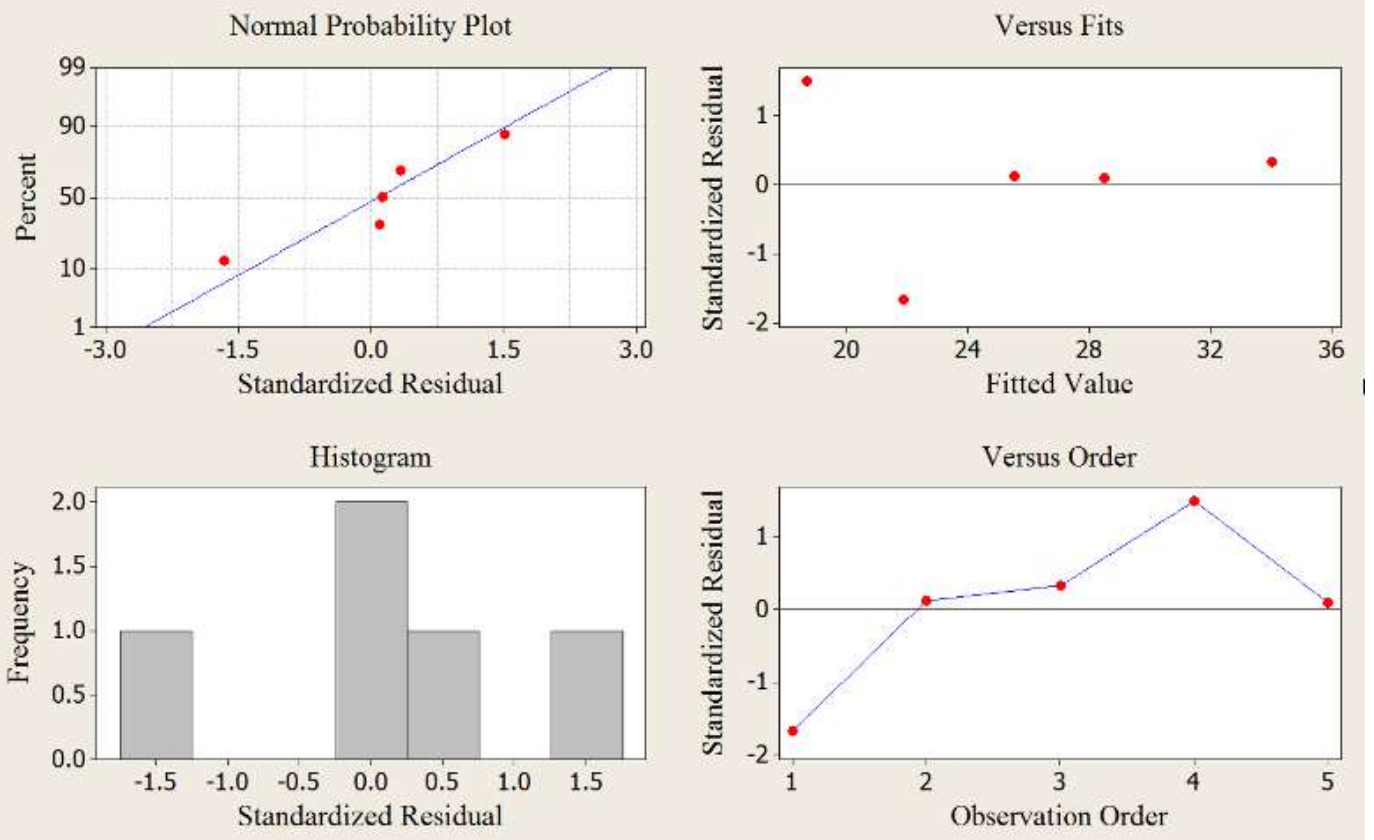